\title{
Network capacity charge for sustainability and energy equity: A model-based analysis
}

\author{
Kaveh R. Khalilpour ${ }^{1,2, *}$, Peter Lusis ${ }^{2}$ \\ ${ }^{1}$ School of Information, Systems and Modelling, Faculty of Engineering and IT, University of \\ Technology Sydney, Sydney, NSW, Australia \\ ${ }^{2}$ Faculty of Engineering and Information Technology, Monash University, Melbourne, Australia \\ *Corresponding author email: kaveh.khalilpour@uts.edu.au
}

\begin{abstract}
:
It is long known that the afternoon peak demand accounts for over-investment in the electricity network assets. This results in a high price of delivered electricity which does not fairly differentiate between peak and non-peak users. Energy tariff is proven to be one of the best demand-side management (DSM) tools for shaping consumers' behaviour. While electricity pricing models, such as inclining block and time-of-use tariffs, have received decent attention as successful mechanisms, there are little discussions about another efficient tariff known as a rollover network capacity charge. It is a penalty for the highest recorded power usage over the previous reading cycle (or year) which is introduced to commercial users in some jurisdictions.

With recent price reduction in distributed generation and storage (DGS) systems, the interest has increased in devising policies for directing the household and commercial consumers' behaviour towards using DGS systems in line with DSM objectives. In this paper, we have integrated the rollover network capacity charge into DGS systems investment analysis. The results from a few case studies show the positive impact of capacity charge in directing the peak-consumers' investment decisions towards DSM tools (e.g., energy storage) to curb their peak demands. This not only improves the resilience of the network but also promises as an effective mechanism in energy-justice nexus by avoiding the transfer of the associated costs of peak demand to all users.
\end{abstract}

Keywords: Energy-justice nexus; energy equity; demand-side management (DSM); distributed generation and storage (DGS); energy storage; rollover network capacity charge; demand charge. 


\section{Introduction}

\subsection{The issue of critical peak demand}

In the electricity market, along with the daily demand peaks, there is another form of a peak known as "critical peak demand (CPD)" that occurs for a limited number of hours during a year. Generally, a CPD is a coincident demand that happens due to air-conditioning use in extreme weather conditions (e.g., very hot summer days) by all consumer types. The electricity supply chain infrastructure (generation, transmission, and distribution) should be designed to satisfy such maximum load incidences. This translates to the development of an oversized infrastructure.

Figure 1 shows the demand profile of New South Wales (NSW), Australia, in 2013. During that year, except for two days, the load was always below $12 \mathrm{GW}$. However, January $8^{\text {th }}$, a summer day, witnessed the fifth hottest day on record, with the ambient temperature reaching $42.3{ }^{\circ} \mathrm{C}$. The consequent air-conditioning usage made a sharp increase in the state-wide demand, reaching almost $13 \mathrm{GW}$ during the afternoon. This was not the only shock to the network that year, as ten days later the temperature reached $45.8{ }^{\circ} \mathrm{C}$. During this hottest day since 1939 , the demand peaked at $13.8 \mathrm{GW}$. Therefore, the critical peak load during two hot afternoons in 2013 necessitated bringing $1.8 \mathrm{GW}$ of extra generation capacity online.

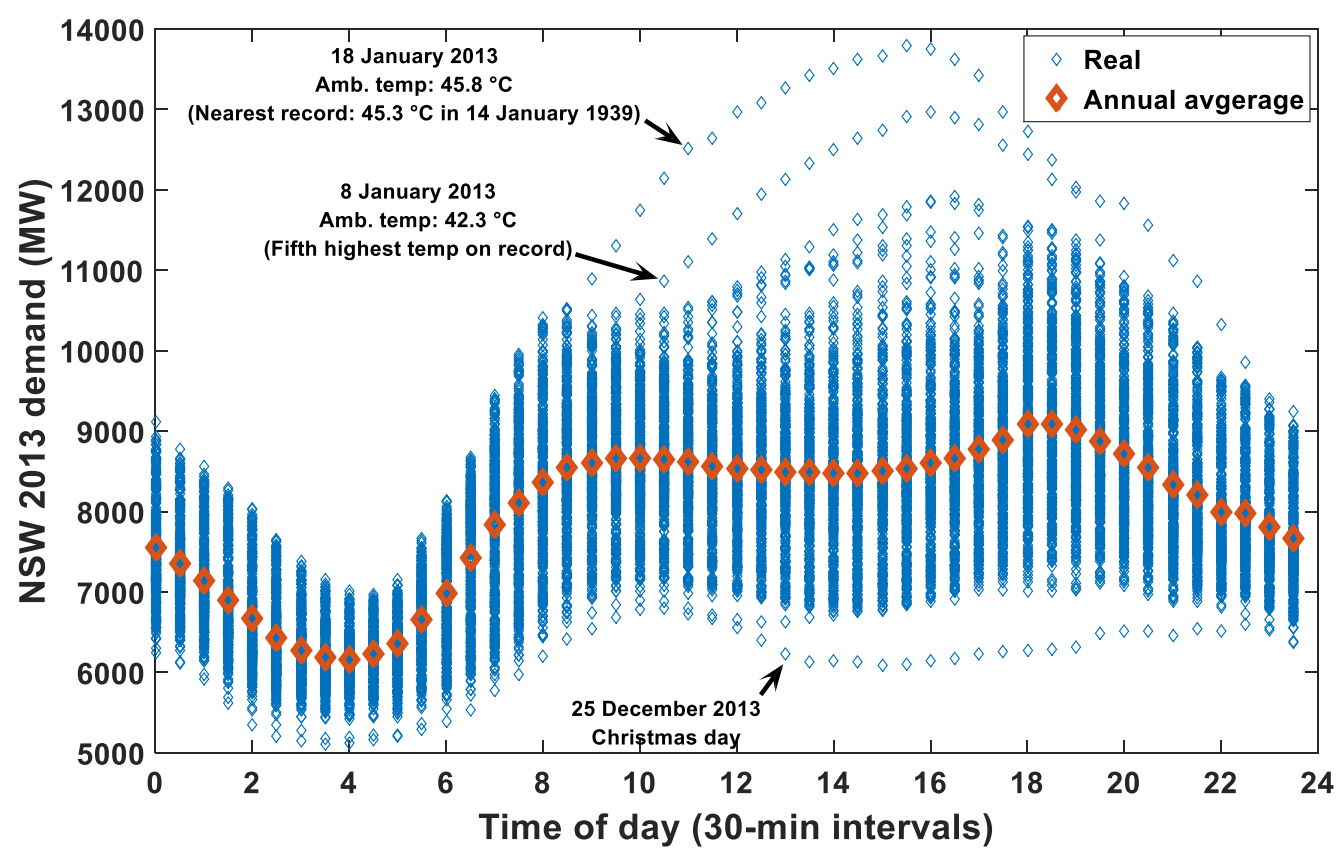

Figure 1: Time of day electricity demand profile of New South Wales, Australia, during 2013 


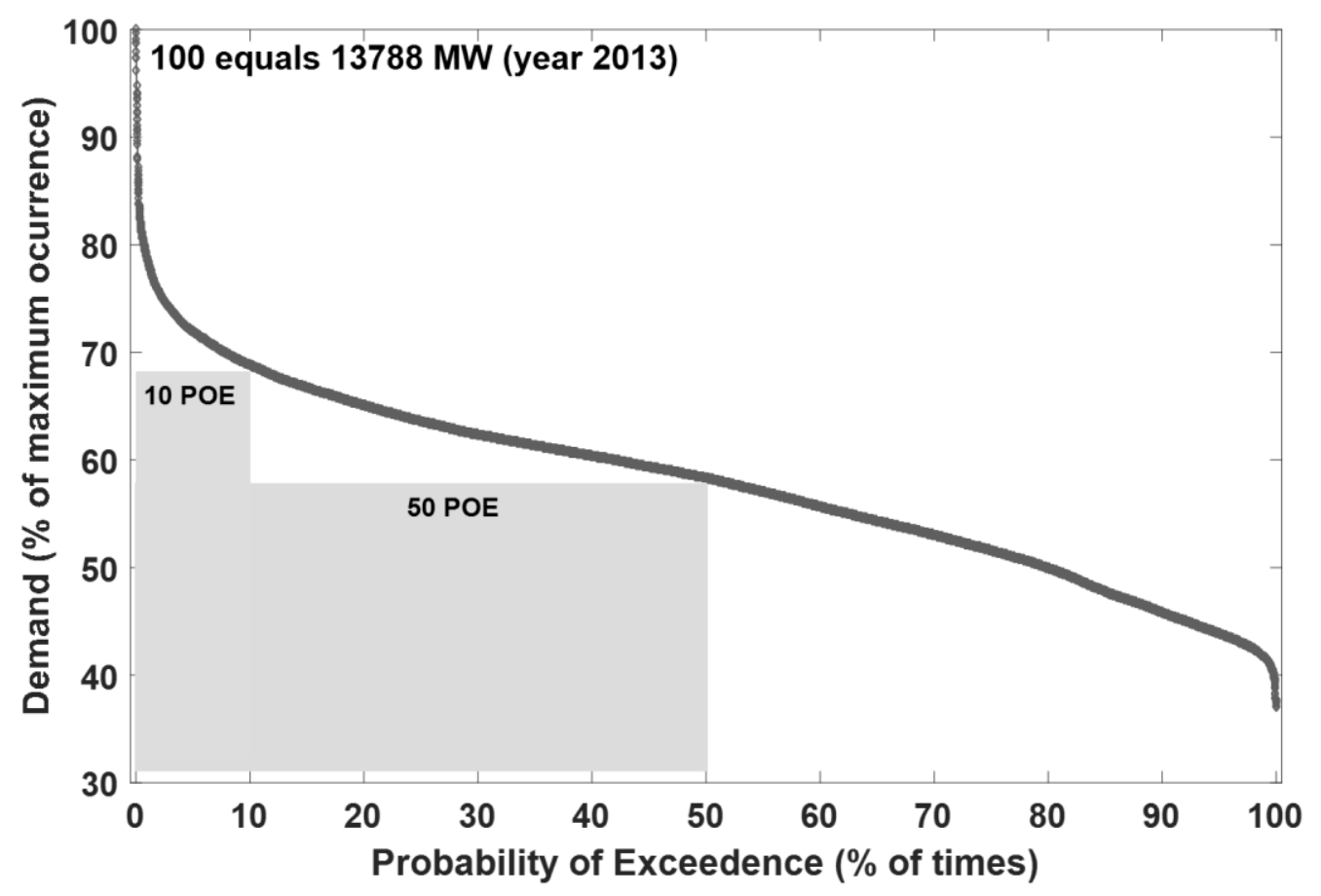

Figure A

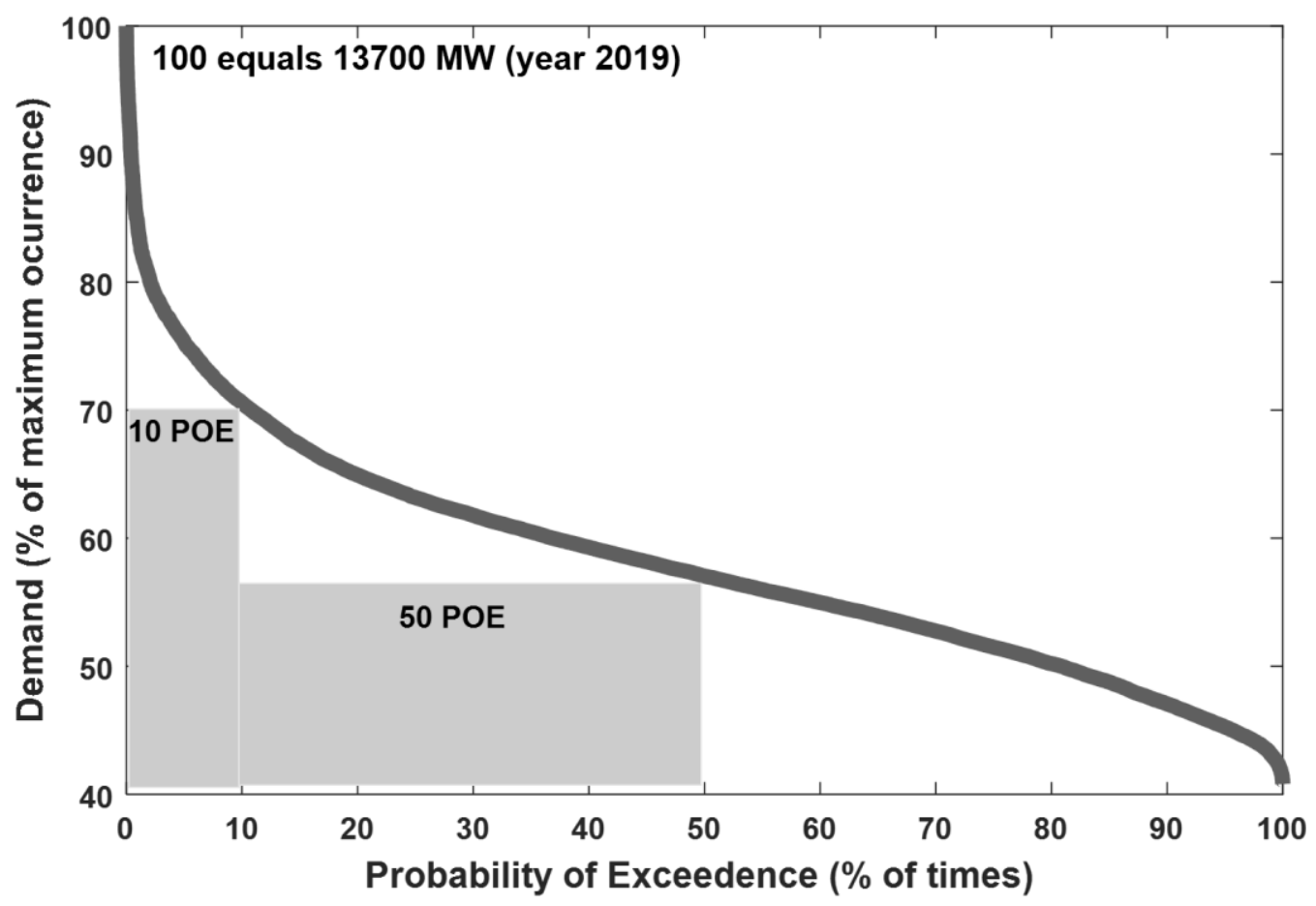

Figure B

Figure 2: Cumulative distribution function $(\mathrm{CDF})$ profile of electricity demand in New South Wales, Australia, during 2013 (A) and 2019 (B)

The cumulative distribution functions (CDFs) of the same load of Figure 1 is illustrated in Figure 2A. The probability of exceedance (POE) value of 100 in the Y-axis is identical to the maximum demand occurrence during that year (i.e., 13.8 GW). The 50 POE line shows that 
the demand was less than $58.4 \%$ of the maximum occurred load (i.e., $8 \mathrm{GW}$ ) over half of the times. According to the 10 POE line, over $90 \%$ of the times, the demand was less than $68.8 \%$ of maximum load. More interestingly, $99 \%$ of the times the demand was satisfied with less than $78.7 \%$ of the maximum load. In other words, $21.3 \%$ of the generation capacity was used only during $1 \%$ of the times. Figure $2 \mathrm{~B}$ shows more updated data, for 2019 . For this year, the $50 \mathrm{POE}$ and 90 POE lines cross, the curve at $57.0 \%$, and $70.6 \%$, respectively. In $2019,15.7 \%$ of the generation capacity was used only during $1 \%$ of times.

A simple definition of reliability is the extent of the demand that a supply chain is capable of delivering within a certain timeframe, which can be for instance quantified with the loss of load probability (LOLP) [1]. This example clearly shows the detrimental role of CPD in the network asset investment and supply reliability. Therefore, the consequent question is how to address demand volatilities, in general, and CPD particularly, in a reliable energy supply chain planning. There are two demand management approaches: A) passive, and B) active illustrated in Figure 3 and described next.

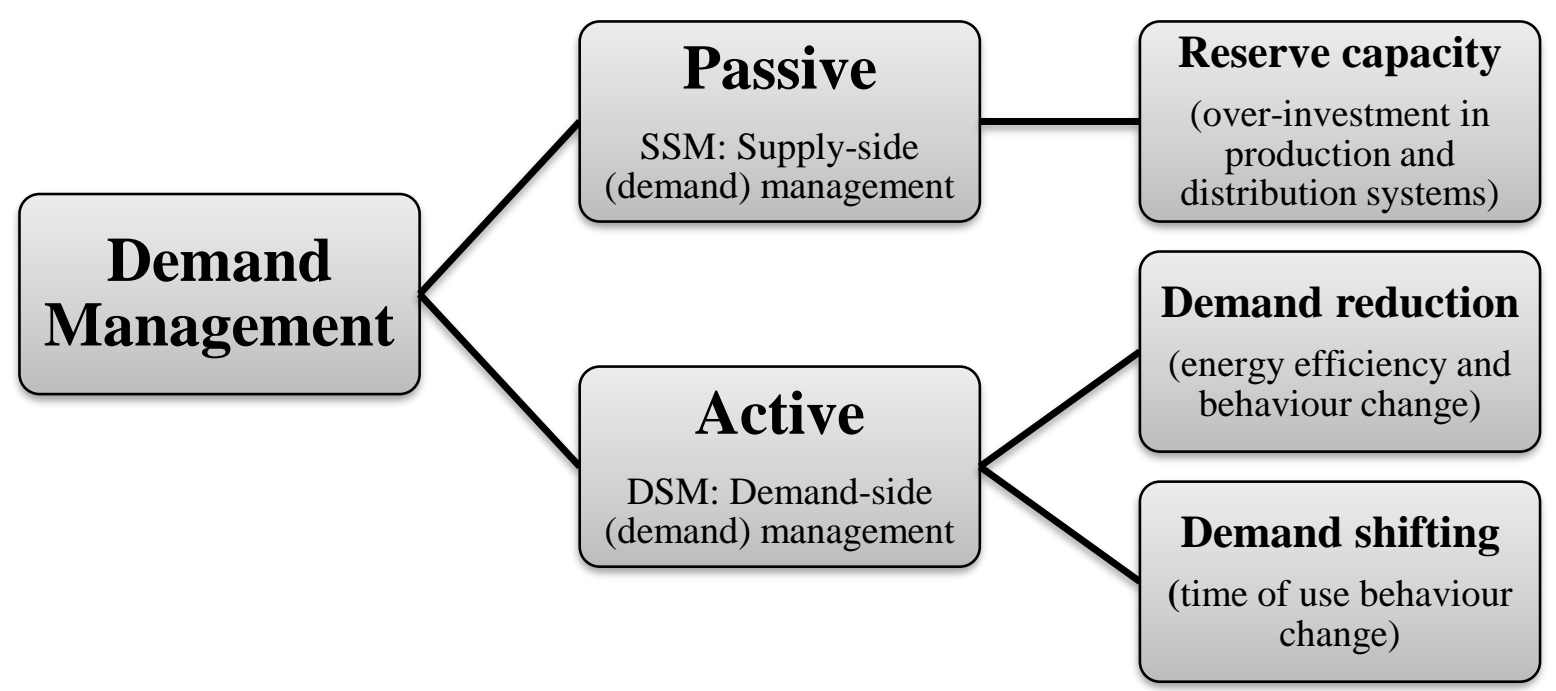

Figure 3: Approaches for demand management

\section{A) Passive demand management: Supply-side management}

Passive demand management takes the historical and forecast demand as a base, and attempts to supply it with the specified reliability standards. For this, a supply chain operator develops its planning based on the occurrence of the maximum projected demand during the planning horizon. This includes considerations of some reserve capacity for the security of supply in case of any component failure or critical demand (See Figure 4A). This capacity margin 
depends on the POE basis of the investment. The lower the POE value, the higher would be the installed capacity and the lower would be the reserve capacity (See Figure 2).

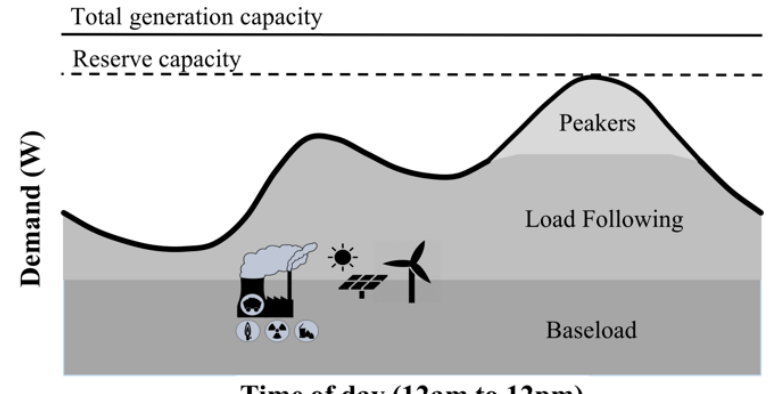

Time of day (12am to 12pm)

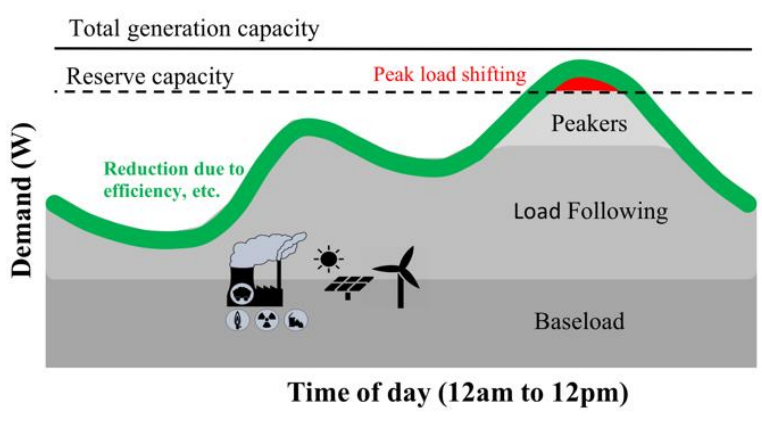

Figure B

Figure 4: Schematic of demand management in the electricity supply chain: A) Passive, with supplying the demand, B) Active, with energy efficiency measures and load shifting

Generally, reserve capacity can be as high as $20 \%$ [2]. A high reserve generation capacity is not the only burden of volatile demand. The transmission and distribution network also needs to be designed based on the peak load conditions. Today, therefore, we have (at least across industrialized countries), overly-invested electricity grids with a significant part of the fleet being utilized for a limited number of hours per year. This is to satisfy social welfare in terms of 24/7 continuous access to electricity, even in extreme weather conditions. Of course, this welfare comes with elevated delivered energy costs. For example, productivity analysis in some jurisdictions shows that $25 \%$ of household electricity bills account for generators that operate for fewer than 40 hours per year (during critical peak demand periods) [3]. On the other hand, in most developing countries, when a high reserve capacity is not an accessible option, the partial blackout is the general consequence of critical demand or component failure. Such pieces of evidence highlight the weakness of passive demand management and the necessity of alternative options. Energy storage at the generation side is another form of passive demand management which attempts to improve supply security and also reduce emissions footprint with the highest renewable energy utilization.

\section{B) Active demand management: Demand-side management}

Active demand management is, in fact, reverse demand management in which network operators attempt to reshape customers' demand profile rather than over-investing in reserve capacity (See Figure 4 right). This is known today as demand-side management (DSM). It was in the early 1970s that the shock in energy prices drew attention towards energy efficiency and productivity, and when DSM became a field of research and development in the academic 
forum [4]. DSM can be categorized into two groups: (1) load reduction through energy efficiency and conservation, and (2) load shifting through demand response (See Figure 4 right). A detailed review of these approaches is provided elsewhere [5].

The significance of energy efficiency is evident. Demand response, however, comprises endless innovative techniques with the goal of flattening the load curve by shifting the demand from the peak to non-peak periods. Time shifting of demand has proven to be one of the most effective approaches for improving reliability and reducing the supply chain delivery costs of commodities.

\subsection{Smart and fair tariffs for active demand management}

According to McKinsey, active DSM has six levers: tariff rates, incentives, information, control, education, and customer insight and verification [6]. Although a fraction of customers, given education and insight, might take voluntary actions to participate in demand response, for most people active incentives (e.g., low tariffs for off-peak) or passive incentives (bill rebate after participation) would be detrimental to participation.

Energy storage technologies are great DSM options. However, there are two concerns, one being the cost and efficiency of storage technologies [7]. The other and the most critical concern is that they cannot support the network alone, and they will be effective when combined with smart tariffs [4]. Smart tariffs have proven to be the most influential tool in demand-side management [8]. Allcott et al. [9] showed that real-time pricing is more efficient than a flat fee structure. A study by the Energy Networks Association (ENA) demonstrated that both time-based and market price-based tariffs have a positive effect on peak-demand reduction compared to a flat-tariff [10]. Sterioitis et al. [11] showed that tariffs could be tailored down to individual customers based on their consumption behaviour.

Not only could the design of smart tariffs reduce the peak load, but it can also be a useful tool in the hands of policy-makers for designing fair pricing mechanisms to improve social equality in the energy-justice nexus. For instance, the Productivity Commission of Australia has given an interesting example: "Currently, a low-income household without an air conditioner is effectively writing cheques to high-income users who run air conditioners during "peaky" periods. For example, a household running a two kilowatt (electrical input) reverse cycle air conditioner, and using it during peak times, receives an implicit subsidy equivalent of around $\$ 350$ per year from other consumers who do not do this" [3]. More examples of tariff discrimination are discussed by Simshauser [12]. Therefore, a smart tariff would incentivize customers who consume less energy during peak times and increase the charges of peak users. 
In brief, when households and businesses are not exposed to time-based, cost-reflective network pricing, they lack encouragement to shift their consumption away from the peak demand periods. This leads to an over-investment in peak-specific systems and grid reinforcement as well as higher fuel costs through increased ramp rates, thus, reducing the social benefits for the consumers [13]. Consequently, these costs are shared equally, but unfairly, between peak and non-peak consumers.

\section{Time of use and inclining block tariffs}

There are currently two main tariff structures in effect internationally: inclining block and timeof-use (ToU). Figure 5 shows the schematics of the inclining block and ToU tariffs, respectively. The inclining block might be a good tariff for network-based commodities such as water and gas. Its effectiveness for electricity peak management is however questionable. In this tariff, the electricity price increases with the accumulative energy consumption over a certain period (e.g., month or season). Therefore, this method contributes to the DSM by encouraging customers to reduce their overall consumption, but it lacks any mechanism to address peak consumption. Furthermore, it is arguable that the inclining block is not a fair mechanism as it does not differentiate between the inhabitant numbers per connection point. For instance, a household of five would end up paying more per unit of electricity consumed than a household of two, even with lower energy consumption per capita. On the other hand, the ToU mechanism tackles peak demand by offering a relatively high tariff during peak periods. This can be socially fairer and technically more effective, though it does not address overall consumption reduction.

Currently, a critical philosophical question around consumption behaviour is almost emerging. The widespread uptake of clean, renewable technologies, such as photovoltaic (PV) cells, can bring us sustainable and affordable energy at near-zero-emissions. We have been educated to consume less following social, ethical, and sometimes religious norms. But, will renewable energies affect this norm? Why not have over-shiny houses at night when the energy is supplied by the wind? The findings in Fikru et al. [14] suggest that households with own energy resources consume more energy than those without.

It can also be anticipated that utilities will shift away from providing energy commodities to providing energy services [15]. The fierce competition among retailers further encourages innovative energy services to reflect the changing consumer expectations [16]. Inching block tariffs are set based on a socialist assumption which does not encourage overconsumption. It 
is expected that at least in countries without subsidized energy costs, block tariffs might be retired over time and different types of time-based tariffs are introduced to reflect the variability of renewable resources. Fairness is also critical for renewable energy feed-in tariffs [17], and for the same reasons discussed here for energy purchase, ToU tariff may prevail flat tariff for energy export, from both fairness and DSM aspects.

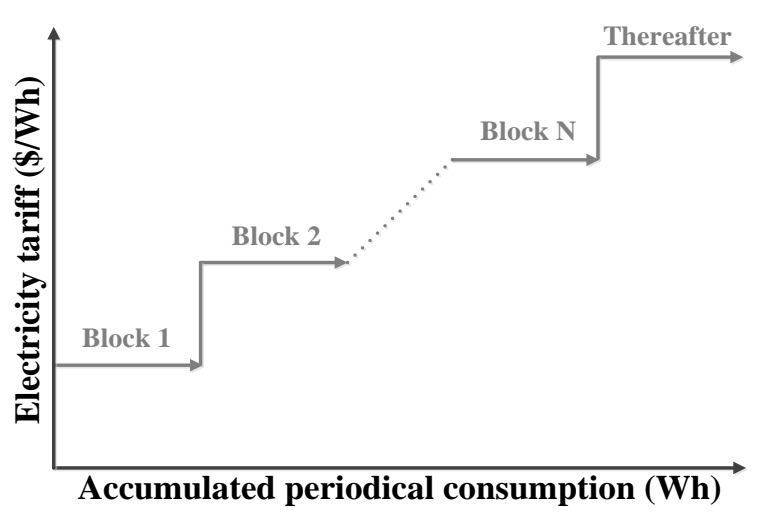

Figure A

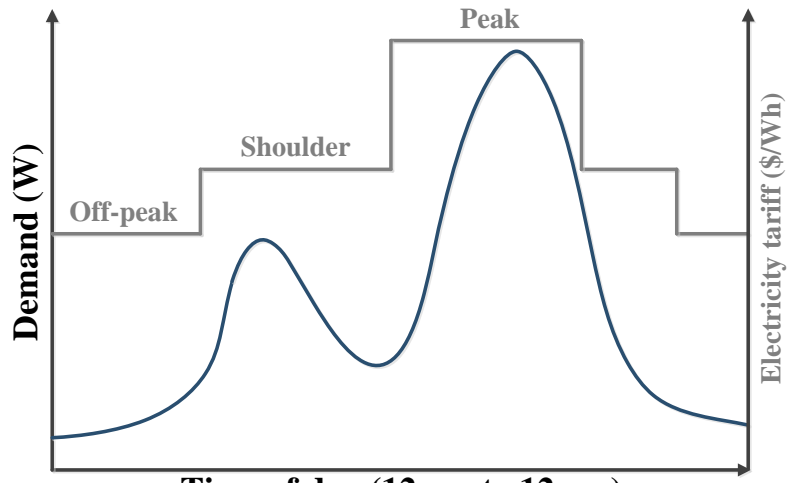

Time of day (12 am to 12 am)

Figure B

Figure 5: Schematic of A) inclining block energy tariff, and B) time of use energy tariff

\section{Rollover network capacity charge}

So far, two major tariffs for targeting overall energy consumption and peak period demand are discussed. However, there is evidence that none of these can address the critical peak demand efficiently (See Figure 1 and Figure 2 as an example). One approach to address this problem, especially on a community scale, is dynamic pricing [18]. Alternatively, some supply chain companies introduce a rollover network capacity charge, also known as network charge, capacity charge, or demand charge. It is composed of a fixed number (\$/power/time) multiplied by the highest demand occurrence during the previous billing period at a given measured interval of the smart meter (e.g., kW), multiplied by time. For instance, assume the capacity charge is based on the highest occurrence in the previous year. For a given company, the occurred highest demand was $1000 \mathrm{~kW}$ with a capacity charge of $130 \$ / \mathrm{kW} / \mathrm{year}$. This translates to $\$ 130,000$ added to the bill. Now, imagine that the company's load was almost always below $700 \mathrm{~kW}$, and it exceeded this number only a few times in a hot summer. This implies that the company is paying $(1000-700) \times 130=\$ 39000$ extra over this year because of those few critical demand incidences rolled over from last year. Obviously, any user will source for options to avoid its critical peak demand. At a macro level, this demand-side behaviour is 
expected to reduce the critical peak demand at the generation and transmission side, and thus reduce the need for large reserve capacity (See Figure 2).

Historically, users with capacity charge tariffs, especially commercial buildings, have managed their critical demands through efficiency and flexibility measures [19]. In recent years, energy storage has been attracting interests from peak-users to provide them with flexibility in their demand management. The principle of equity requires that any tariff design fully reflects the supply costs and provides investment signals. However, with high installation costs of energy storage systems, this option is not yet a widespread feasible choice if only inclining block or ToU is considered. The capacity charge can help to achieve more cost-reflective electricity network tariff. However, its effectiveness depends on whether the customer's coincident demand occurs at the time when network peaks are likely to occur [20]. Though the capacity charge is often introduced for commercial and large-scale consumers, some studies show the efficiency of this tariff even for residential customer [21]. Young et al. [22] simulated various tariff designs for the operation of household PV and energy storage and found that incorporating capacity charge in the tariff design yielded the highest peak demand reduction. This becomes particularly noticeable in the networks where the dominant cost driver is the required reserve to meet the highest electricity consumption. The need for the capacity charge to facilitate the uptake of energy storage is further supported by Stelt et al. [23] who found that under the current storage investment costs and energy tariffs energy storage is economically infeasible for households.

The capacity charge has another benefit of managing the negative load (export from renewable generators) or shifting coincident peaks from one period to another. However, Eid et al. [24] emphasized that capacity charge can be considered effective only if the peak load is clipped or distributed over a longer time period instead of shifting it to another time period. The capacity charge can be enabled only if an advanced metering infrastructure (AMI) is deployed in the network. Hakyoort et al. [25] highlighted that the problem of split-incentives related to the AMI would discourage a distribution system operator (DSO), retailer or a customer to be the sole entity that makes the investment. Khalilpour and Vassallo [4] have discussed the concern over the emergence of new peak demands in times other than the current afternoons. They have also discussed the potential problems with sharp changes in load profiles during the periods at which ToU tariffs are shifting from one threshold to another. In a typical energy storage operation program, there are constraints to control the storage charge rate and also prevent the storage SOC from being above/below a maximum/minimum. Other constraints limit the battery 
charge/discharge rates at design charge/discharge caps. While these are valid constraints, there can still be a problem. The issue is that the off-peak period is typically close to 10 hours (from late night to early morning) while a battery with C-rate of 0.5 requires only two hours for a full charge. This two-hour period could occur at any time within the 10-hours of off-peak period. A severe grid management problem could occur when all batteries are programmed to charge (or discharge) at a similar time. This has been demonstrated in the literature for causing a new peak in a common off-peak period [4]. Similar to our morning peaks (e.g., for hot water use) the future houses with stationary battery and electric vehicles (EVs) may cause sharper morning peaks. Imagine when people wake up in the morning, one or two hours before the shift of electricity tariff from off-peak to shoulder/peak. The immediate thing they might think of would be to plug in their storage systems. With the rapid uptake of stationary batteries and EVs, such problems could easily occur unless smart storage control systems, along with smart electricity tariffs, are introduced.

To avoid this, one approach is to add a further random constraint, so-called "operational charge limit (OCL)," for off-peak periods in order to distribute the battery charge over the entire offpeak period [4]. This prevents charging to be delayed until the last one or two hours before tariff change. While this constraint proved to work efficiently, it is not a binding constraint for customers to use and in practice, unwanted new demand peaks are possible in future. Capacity charge, however, is not time-relevant and can be used as an enforcing tool by policymakers for encouraging customers to reduce their peak at any time during a day. With a capacity charge, there might be less or no requirement for OCL constraints.

Currently, in most energy storage investment analyses, the benefit of capacity charge is not considered, while this can notably improve the value proposition of energy storage options. There could be various reasons for ignoring capacity charge ranging from the inexistence of such tariff mechanisms in some jurisdictions to the complexity of bringing it to the optimization problem formulation. The key objective of this study is to bring rollover network capacity charge constraints into distributed generation and storage systems' sizing and scheduling, and assess how it can affect the decisions.

\section{Literature on sizing and operation modelling of distributed generation and storage}

Today, renewable energy technologies are no more topics of merely academic interest. Fortunately, renewable energy is finding its way into our fossil-fuel-based energy industry and even to our rooftops. Distributed energy resources have several advantages, including 
abundance and relatively scattered geographic distribution. As such, exploring the utilization of local (renewable) energy sources has been a matter of economic benefit and security for energy-importing societies. Furthermore, the possibility of generating energy on the demandside has many advantages in terms of energy efficiency, as it can reduce the required reserve generation capacity, lessen the network footprint, and minimize the power losses in the transmission system network. All these features have stimulated the idea of moving from traditional, often low-efficiency, and centralized macrogrids to a decentralized form with numerous small but smart grids fueled by local resources.

Various combinations of energy generation and storage technologies have been studied. For obvious reasons, solar systems have been of the highest interest for small-scale demand-side applications. The earliest simple configurations were PV-grid, PV-diesel [26], and PV-battery. The configurations have diversified over time with the inclusion of various hybrid DGS systems such as PV-hydrogen, PV-diesel-battery [27], PV-wind-battery [28], PV-wind-diesel [29], PV-wind-diesel-battery [30], and PV-wind-diesel-hydrogen-battery [31]. The list of configurations could be much longer if other generation types (e.g., bioenergy, hydro, gas turbine) and storage (e.g., hydro, compressed air, flywheel, capacitance, chemical conversions) are included [32]. For energy network planners and operators, DGS provides a great degree of freedom for DSM through load shifting, if efficient rules and regulations for the operation of the DGS systems are implemented.

Table 1 lists some key literature on the optimal sizing and operation of DGS systems. The first and most crucial step in DGS decision-making is the selection of the right technology, right mix, and right sizes. Then comes the reliable operation of the selected technologies. Initial efforts in the sizing of DGS systems were related to the integrated PV-battery systems. The studies focused mainly on off-grid and rural areas, using approximate methods which resulted in over-sized or under-sized systems [33]. Later, iso-reliability curves were introduced by Egido and Lorenzo [34] which are based on developing numerous graphs of PV-storage sizes, each at a certain reliability value. A good review of the iso-reliability method and a rule-ofthumb approximation on that basis is given by Egido and Lorenzo [34]. As computers emerged, PV-battery sizing models also improved in rigorousness. For instance, instead of daily average solar irradiation or load data, real historical time series were used [35, 36], or characteristic equations were used instead of simple efficiency values for PV panel, battery, inverters [37], etc.

With the global attention to the PV transformation within the last decade, there has been an increasing interest in linking PV and/or battery systems with the electricity market and a need to 
develop an optimal operation schedule. Lu and Shahidehpour [38] developed a short-term scheduling model for battery use in a grid-connected PV-battery system using a Lagrangian relaxation-based optimization algorithm to determine the hourly charge/discharge commitment of a battery in a utility grid. They used an eight-bus test system as a case study and investigated the impact of the grid-connected PV-battery system on locational pricing. Kaushika et al. [39] developed a linear programming formulation for a stand-alone PV-battery system with an objective to find out the optimum combination of the number of batteries and PV modules to allow the operation of the system with zero loss of power supply probability or 100\% reliability. Pham et al. [40] examined five energy storage technologies and found that Li-Ion battery has the highest suitability index to support a stand-alone PV system. A study to find the optimum ESS size considering different battery chemistries was carried out by Hesse et al. [41]. The results showed that lithium-nickel-manganese-cobalt battery is more economically effective for residential application with annual demand bellow 20,000 kWh, while lithium-iron-phosphate batteries are better for households with large demand.

Some researchers have also used artificial intelligence techniques [42] or heuristic optimization techniques, such as particle swarm optimisation (PSO) [43] and metaheuristics with MINLP [44] for sizing PV-battery systems. Riffonneau et al. [45] presented a dynamic programming methodology for "day-ahead" predictive management of grid-connected PV systems with storage. The program, which also considered battery aging, successfully achieved its peakshaving goal at minimum costs. Yu et al. [46] studied the problem of determining the size of battery storage for grid-connected PV systems. They proposed lower and upper bounds on storage size and introduced an optimization algorithm for finding the optimal battery size. They identified a unique critical value for battery size, below which the total electricity cost was high, whereas, above that, increases in battery size had no impact on costs. Ratnam et al. [47] developed a framework based on quadratic programming which enabled the customer to justify expenditure on battery storage either through a least-cost option of capital investment or through choosing to utilize existing electric vehicle battery storage, if available.

Some researchers have focused on the efficient operation of PV-battery systems. According to Halliday et al. [48], though PV systems account for a significant part of the initial investment in PV-battery systems, their share of lifetime capital cost (over 20 years) of the system is around one-third. This is while batteries account for half of the total capital cost due to a lower expected lifetime as a result of inefficient battery operation (high temperatures, low SOC, etc.). As such, optimal control of battery charge/discharge (SOC) is a key component in improving the economics of the overall system $[49,50]$. One of the earliest studies of efficient battery 
operation was by Appelbaum et al. [51], who developed geometrical regions on V-I characteristic graphs of solar systems for efficient charge/ discharge of batteries and load control. More recently, Fragaki and Markvart [52] compared modelling and experimental data of PV-battery systems. Although their application of battery charging efficiency reduced the gap between experiment and model, they highlighted the necessity of development of a method to account for system memory effects imposed by the operation of the charge controller.

Pedram et al. [53] discussed that current homogeneous electric energy storage (EES) systems had limitations in simultaneously achieving desirable performance features such as high charge/discharge efficiency, high energy density, low cost per unit capacity, and long cycle life. As such they proposed the application of hybrid EES (HEES) systems with each EES element having the strength in certain performance feature. Stadler et al. [54] developed a distributed energy resources customer adoption model (DER-CAM) based on a mixed-integer optimization program. DER-CAM can also model various DG and storage types. Mashayekh et al. [55] improved the DER-CAM model by formulating multi-node design to account for the cable losses.

Wang et al. [56] developed a dynamic programming model for the integration of a residentiallevel HEES system for smart grid users equipped with PV power generation. The program objective was to reduce the total electricity cost over a billing period and to perform peak power shaving under arbitrary energy prices, also considering the characteristics of different types of EES elements, conversion efficiency variations of power converters, as well as a time-of-use(ToU) dependent energy price function. They reported up to $73.9 \%$ profit improvement when using a combination of Li-ion and lead-acid batteries compared with single-EES systems. The same group studied various aspects of HEES systems, namely networked architecture [57], balanced configuration [58], and charge allocation and replacement [59, 60]. Manshadi and Khodayar [61] identified the vulnerable components and studied the potential causes of disruptions in multiple energy carrier microgrids.

Abdulla et al. [62] found that accounting for battery degradation and including even simple load and generation forecast models can significantly increase the value and performance of energy storage systems. Khalilpour and Vassallo [4, 63] developed a few integrated decision support tools for concurrent optimal selection, sizing and operation scheduling of gridconnected DGS systems (including but not limited to PV-battery). The importance of the optimal location for ESS was also emphasized in Novoa et al. [64] and Alsaidan et al. [65]. Atia and Yamada [66] built an energy system operation model based on Newton-Raphson Linear Programming (NRLP) algorithm. This model iteratively schedules resources to 
maximize profits while compensating for the complicated nonlinear nature of the problem. An optimal combination of DGS system candidate units was found using a genetic algorithm (GA). The initial combination of units was randomly generated and separately evaluated using the NRLP algorithm. Xiang et al. [67] argue that the real peak demand can occur between discrete time steps and proposes a continuous approximation for the state of energy function using Fourier-Gegendere series to address this problem.

EINozahy et al. [68] used a probabilistic sizing of battery storage. The uncertainties associated with the local power supply and demand were addressed through multiple PV and load profiles; generated using principal component analysis (PCA). The supply and demand profiles from the PCA were then employed in a Monte Carlo (MC) simulation to obtain random load profiles. Their model resulted in lower voltage fluctuations and network losses. Bai et al. [69] reduced electricity costs and network losses in the distribution network using a virtual portioning model. It takes the minimum annual cost as the upper-level objective to determine the investment in PV systems and the minimum sum of equivalent load variance as the lower level objective through the virtual partition to determine the energy storage configuration.

Umeozor and Trifkovic [70] proposed a microgrid management strategy where the variability and uncertainty of renewables are solved with the parametric optimization approach (p-MILP), thus removing the dependency of the solution on weather and load forecast data. Zhou et al. [71] introduced a multi-objective sizing and optimization of DGS systems including demand response. Assuming a linear relationship close to the market equilibrium point, Zhou et al. established an electricity price elasticity matrix based on historical data and compared models with and without demand response. An improved non-dominated sorting genetic algorithm (NTGA II) was used to find the optimal DGS capacity. They found that adding demand response in the optimization model reduces the required PV and battery storage capacity. Demand response constraints also have a positive effect on maximizing profits for microgrids with combined heat and power (CHP) plants as found by Alipour et al. [72]. Storage sizing based on stochastic network calculus (SNC) with a tie line penalty constraint ensured balanced microgrid operation during import/export transition periods in Xie et al. [73]. Pandžić's model [74] is a deterministic battery sizing with consideration of ToU tariff. However, the model is integrated with various load scenario sets to accommodate the uncertainty in the future demand profile.

The capacity charge is not a new tariff. However, there is a gap in the literature on bringing this tariff into optimization framework in the context of DGS systems. In this paper, we 
integrate capacity charge constraints with energy storage sizing and scheduling algorithm. For the sake of paper continuity and in favour of readers with broader interests we have provided the full formulation in Appendix 1. Unlike the current application of capacity charge for the import from the grid, we anticipate that in the future, there might also be a requirement for such a capacity charge for energy export to the grid. As such we consider two capacity charges; one for export, and one for import. We assess the impact of capacity charge consideration in DGS systems selection, sizing, and operation. We also investigate the inherent performance of such a tariff in active demand-side management. The most relevant paper for the sizing and operation of ESS are summarized in Table 1. 
Table 1. Key literature on the optimal sizing and operation of DGS. The following abbreviations are used: WT - wind turbine, CHP - combined heat power, FC - fuel cell, GT - gas turbine, $\mathrm{G}$ - genset.

\begin{tabular}{|c|c|c|c|c|c|c|c|c|c|c|c|}
\hline \multicolumn{3}{|c|}{ Study Model } & \multicolumn{3}{|c|}{ Network Considerations } & \multicolumn{5}{|c|}{ Tariff Considerations } & \multirow[b]{2}{*}{ Reference } \\
\hline & Operational Criteria & Operational Model & Application & $\begin{array}{c}\text { Additional } \\
\text { Components }\end{array}$ & $\begin{array}{l}\text { Network } \\
\text { topology }\end{array}$ & Fixed Price & ToU & $\begin{array}{c}\text { Capacity } \\
\text { Charge }\end{array}$ & Spot Price & FIT & \\
\hline- & Cash Flow & Mathematical (DP) & DER & PV & & $\checkmark$ & & & & $\checkmark$ & {$[45]$} \\
\hline- & Energy Costs & Mathematical (QP) & DER & PV & & $\checkmark$ & & & & $\checkmark$ & [47] \\
\hline- & Energy Costs & Analytical (geometrical) & DER & PV & & $\checkmark$ & $\checkmark$ & & & $\checkmark$ & [49] \\
\hline - & Energy Costs & Analytical & DER & PV & & $\checkmark$ & $\checkmark$ & & & & [14] \\
\hline - & Energy Costs & Mathematical (p-MILP) & DER & $\mathrm{PV}, \mathrm{WT}$ & & & $\checkmark$ & & $\checkmark$ & $\checkmark$ & [70] \\
\hline- & Revenue & Mathematical (MILP) & Microgrid & WT, CHP, FC & & & & & $\checkmark$ & & [72] \\
\hline \multicolumn{12}{|c|}{ Non-cost-based sizing } \\
\hline ENS & - & Mathematical (LP) & Stand-alone & PV & & & & & & & [39] \\
\hline ENS & - & Analytical (rule-based) & Stand-alone & $\mathrm{PV}$ & & & & & & & [52] \\
\hline ENS & Battery Capacity & Analytical (rule-based) & Stand-alone & PV & & & & & & & [40] \\
\hline Network Congestion & Transformer Overloading & Probabilistic (MC) & DER & PV & $\checkmark$ & & & & & & [68] \\
\hline Zero Net Energy & - & Mathematical (MILP) & Microgrid & PV & $\checkmark$ & & $\checkmark$ & & $\checkmark$ & $\checkmark$ & [64] \\
\hline \multicolumn{12}{|c|}{ Cost-based sizing } \\
\hline NPV & Energy Costs & Analytical (technometric) & DER & PV & & $\checkmark$ & $\checkmark$ & & & $\checkmark$ & {$[50]$} \\
\hline Annualized Costs & Energy Costs & Mathematical (MILP) & DER & $\mathrm{PV}$ & & $\checkmark$ & $\checkmark$ & & & $\checkmark$ & [46] \\
\hline Annualized Costs & Energy Costs & Mathematical (DP) & DER & PV & & $\checkmark$ & $\checkmark$ & & & & [56] \\
\hline NPV & - & Mathematical (LP) & Microgrid & $\mathrm{PV}, \mathrm{G}$ & & $\checkmark$ & & $\checkmark$ & & & [27] \\
\hline Annualized Costs & Energy \& Operation Costs & Mathematical (MILP) & DER & PV & $\checkmark \checkmark$ & $\checkmark$ & & $\checkmark$ & & $\checkmark$ & [55] \\
\hline NPV & Energy Costs & Mathematical (MINLP) & DER & PV & & & $\checkmark$ & & & $\checkmark$ & [63] \\
\hline LCOE & Energy Costs & Mathematical (MILP) & DER & $\mathrm{PV}$ & $\checkmark$ & & & & $\checkmark$ & & [23] \\
\hline Annualized Costs & Energy Costs & Mathematical (GA+LP) & DER & $\mathrm{PV}, \mathrm{WT}$ & $\checkmark$ & & & & $\checkmark$ & & [71] \\
\hline Annualized Costs & Energy Costs & Mathematical (MILP) & DER & - & & & $\checkmark$ & $\checkmark$ & & & [74] \\
\hline Annualized Costs & Energy \& Operation Costs & Mathematical (MILP) & Microgrid & - & & & & & & & [65] \\
\hline Annualized Costs & Energy Costs & Mathematical (MINLP) & DER & PV & & & $\checkmark$ & & & & [44] \\
\hline Investment Costs & Energy \& Operation Costs & Mathematical (MILP) & Microgrid & PV & & & $\checkmark$ & $\checkmark$ & & & [75] \\
\hline Annualized Costs & Energy Costs & Mathematical (LP) & DER & $\mathrm{PV}$ & & $\checkmark$ & & & & $\checkmark$ & [41] \\
\hline Annualized Costs & - & Mathematical (MILP) & Microgrid & PV, WT, GT & $\checkmark$ & & & & $\checkmark$ & & [65] \\
\hline Investment Costs & Energy Costs & Mathematical (SNC) & Microgrid & $\mathrm{PV}, \mathrm{WT}$ & & $\checkmark$ & & & & $\checkmark$ & [73] \\
\hline Annualized Costs & - & Analytical & DER & $\mathrm{PV}$ & $\checkmark$ & & & & & & [67] \\
\hline Investment Costs & Energy Costs & Heuristics (PSO) & DER & PV & & $\checkmark$ & & & & $\checkmark$ & [43] \\
\hline
\end{tabular}




\section{Case studies}

\subsection{With a supply charge}

A supply chain company (here on called "the company") has an inventory in Melbourne, Australia, with an annual electrical load profile given in Figure 6. The inventory has consumed 6,633.7 MWh of electricity over the base year with the load varying between $212.0 \mathrm{kWh}$ and $1344.8 \mathrm{kWh}$ (occurred $6 \mathrm{pm}, 23 \mathrm{Feb}$, a summer day). Almost all of the top 20 peak demand incidences have occurred over Dec-Mar (evident in Figure 6), which are summer months in Melbourne. This implies the use of air-conditioning as a major contributor to peak demand. Table 2 provides an explicit list of electricity tariffs the company has paid with an additional $10 \%$ goods and service tax (GST). The cost is composed of retail charges for the peak and offpeak usage, environmental schemes, network, market operator, and metering. In Table 2, the capacity charge is one of the tariffs under "network charges" category. The company has paid $\$ 908,158.7$ over the year for its electricity bill. Given the capacity charge of $134.7 \$ / \mathrm{kW} / \mathrm{y}$ and the incurred highest demand of $1344.8 \mathrm{~kW}$, the company has to pay $\$ 181,175.4$ as a capacity charge in the following billing year.

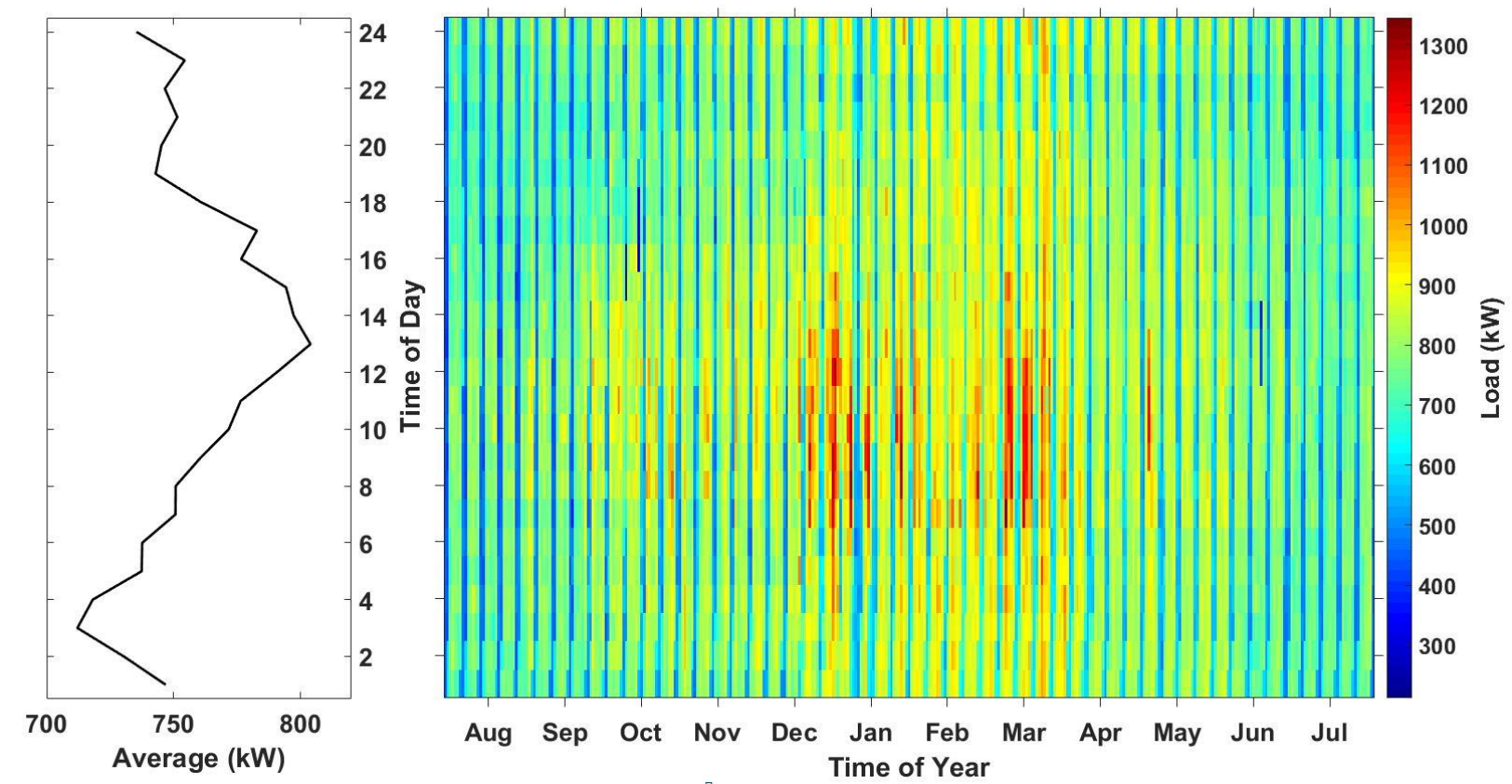

Figure 6: The Company's carpet-plot of electricity load during the base year (July-July); the high demands during Dec-March imply the use of air-conditioning over the summer (for the southern hemisphere).

Given that the declining PV prices, the company is interested to assess the feasibility of investing in PV as well as in battery storage systems. The preferred payback period for the company is less than ten years. 
The candidate PV panels have a standard efficiency of 0.17 . They are available in various sizes, and the company puts no upper limit on the potential system size. The PV output decreases by $0.5 \%$ annually (due to aging). The annual ambient temperature and GHI profiles are illustrated in Figure 7. The recent PV system prices show almost linear functionality with size (though with different multipliers for small-, medium-, and large-scale systems). For this study, the customer considers a linear function for the PV installation cost with a multiplier of $1500 \$ / \mathrm{kW}$.

Table 2: The tariff breakdown of the company's electricity bill with GST of $10 \%$

\begin{tabular}{|c|c|c|c|c|c|}
\hline Charges & Charge type & $\begin{array}{l}\text { Applied to } \\
\text { (unit) }\end{array}$ & $\begin{array}{c}\text { Unit Price } \\
\text { (c/kWh, } \\
\text { unless } \\
\text { mentioned })\end{array}$ & $\begin{array}{l}\text { Loss } \\
\text { factor }\end{array}$ & $\begin{array}{c}\text { Total Unit } \\
\text { Price (excl. } \\
\text { GST) }\end{array}$ \\
\hline \multirow[t]{2}{*}{ Retail Charges } & Peak & $\begin{array}{l}\text { Peak consumption } \\
(\mathrm{kWh})\end{array}$ & 5.0192 & 1.09479 & 5.4950 \\
\hline & Off Peak & $\begin{array}{c}\text { Off-peak } \\
\text { consumption }(\mathrm{kWh})\end{array}$ & 2.9611 & 1.09479 & 3.2418 \\
\hline \multirow{3}{*}{$\begin{array}{c}\text { Environmental } \\
\text { Schemes }\end{array}$} & $\begin{array}{l}\text { Large-scale renewable } \\
\text { energy Certificates } \\
\text { (LRECs) }\end{array}$ & $\begin{array}{l}\text { Total consumption } \\
\quad(\mathrm{kWh})\end{array}$ & 0.9426 & 1.09130 & 1.0287 \\
\hline & $\begin{array}{c}\text { Victorian energy } \\
\text { efficiency certificates } \\
\text { (VEECs) }\end{array}$ & $\begin{array}{l}\text { Total consumption } \\
\quad(\mathrm{kWh})\end{array}$ & 0.4691 & 1.09130 & 0.5119 \\
\hline & $\begin{array}{c}\text { Small-scale renewable } \\
\text { energy Certificates } \\
\text { (SRECs) }\end{array}$ & $\begin{array}{l}\text { Total consumption } \\
(\mathrm{kWh})\end{array}$ & 0.3857 & 1.09130 & 0.4209 \\
\hline \multirow{3}{*}{$\begin{array}{l}\text { Network Charges } \\
\text { (for large low } \\
\text { voltage demand) }\end{array}$} & Peak & $\begin{array}{c}\text { Peak consumption } \\
(\mathrm{kWh})\end{array}$ & 4.7905 & - & 4.7905 \\
\hline & Off Peak & $\begin{array}{c}\text { Off-peak } \\
\text { consumption }(\mathrm{kWh}) \\
\end{array}$ & 2.8514 & - & 2.8514 \\
\hline & Capacity & $\begin{array}{l}\text { Highest demand } \\
\text { occurred }(\mathrm{kW})\end{array}$ & $\begin{array}{l}134.7229 \\
(\$ / \mathrm{kW} / \mathrm{y})\end{array}$ & - & 134.7229 \\
\hline \multirow{2}{*}{$\begin{array}{c}\text { Market Operator } \\
\text { Charges }\end{array}$} & AEMO Ancillary Fee & $\begin{array}{l}\text { Total consumption } \\
(\mathrm{kWh})\end{array}$ & 0.0178 & 1.09130 & 0.0194 \\
\hline & AEMO Market Fee & $\begin{array}{c}\text { Total consumption } \\
(\mathrm{kWh})\end{array}$ & 0.0315 & 1.09130 & 0.0344 \\
\hline Metering Charges & Meter Charge & $\begin{array}{l}\text { Number of meters } \\
(\mathrm{mtr})\end{array}$ & $1120(\$ / \mathrm{mtr} / \mathrm{y})$ & - & 1120 \\
\hline
\end{tabular}




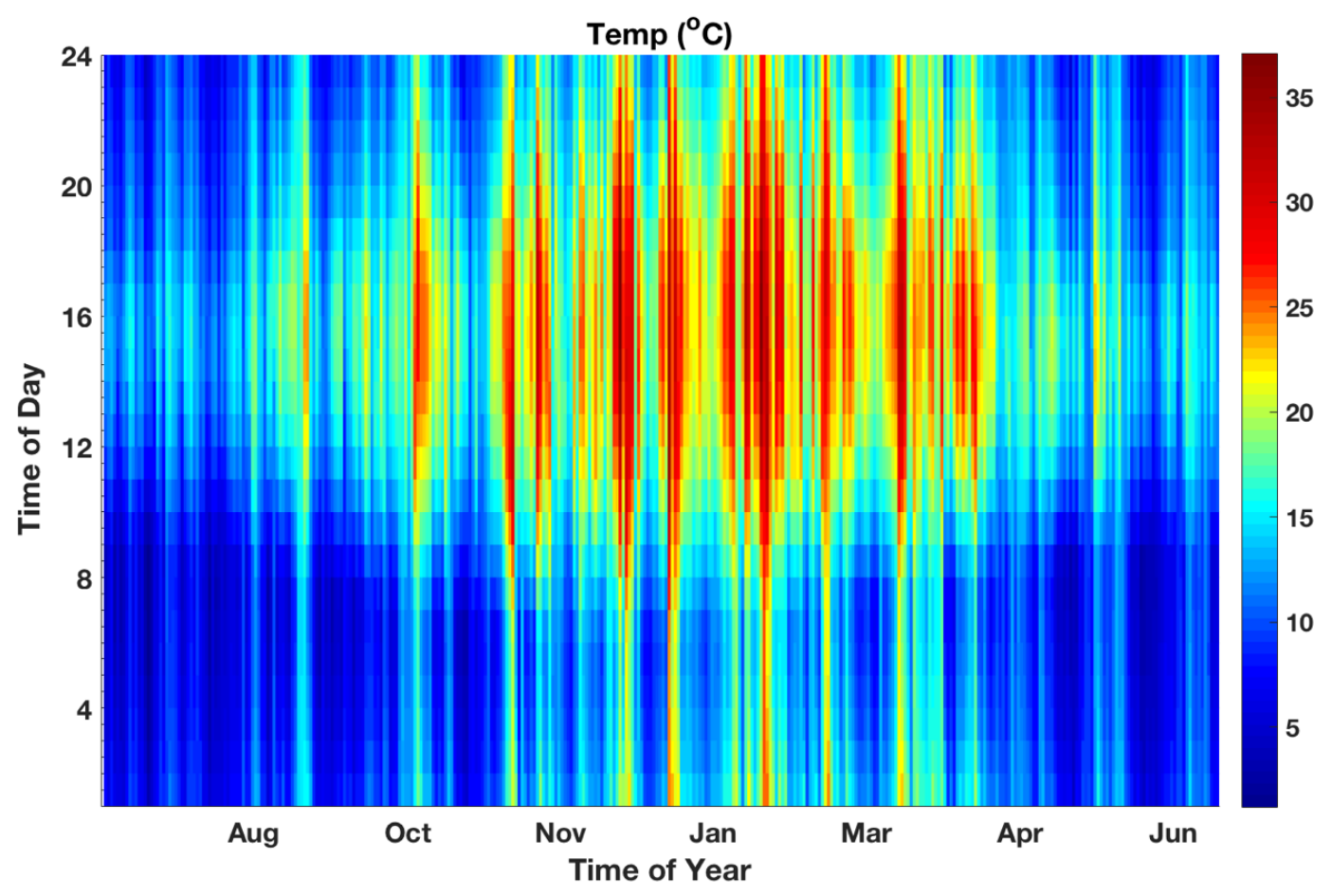

Figure A

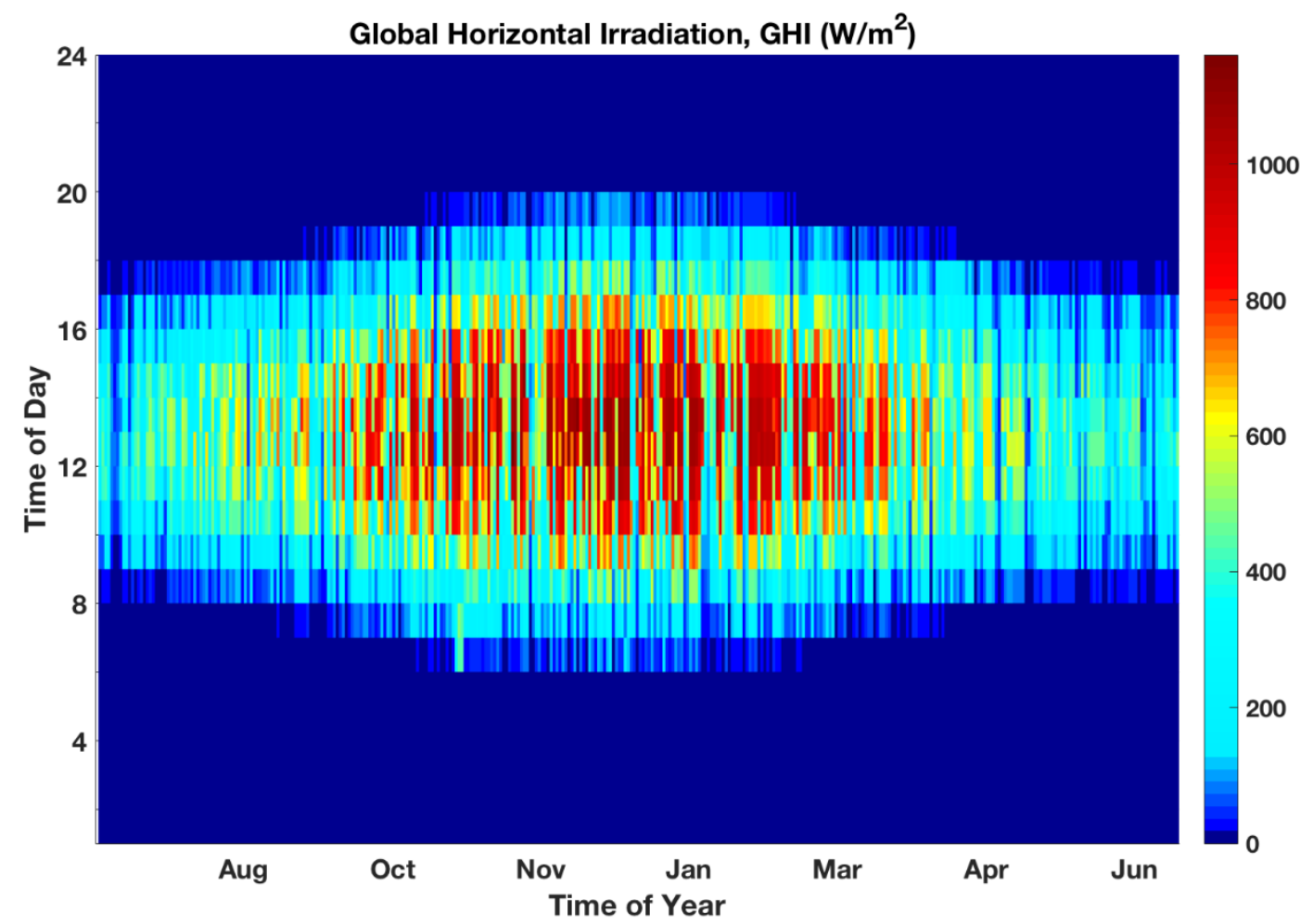

Figure B

Figure 7: Heat map of annual ambient temperature (A) and GHI (B) for Melbourne city (July-June). Please note the seasonal differences of the southern hemisphere.

The company is interested to investigate the feasibility of eight battery types, each with different capacity and techno-economic parameters. Table 3 lists the specifications of the candidate batteries. The installation prices are from [76] with the assumption of a $20 \%$ 
reduction since the year 2012. The selected batteries will operate at a maximum DOD of $85 \%$. The charge controllers and inverters have an assumed efficiency of $98 \%$. The annual maintenance cost of the PV system is $0.5 \%$ of its capital expenditure (CAPEX), while it is $1.0 \%$ for batteries [4].

Table 3: Techno-economic specifications of the candidate batteries for the hospital (the parameters are mainly from [76])

\begin{tabular}{|c|c|c|c|c|c|c|}
\hline $\begin{array}{r}\text { Candidate } \\
\text { battery No. }\end{array}$ & Battery type & $\begin{array}{c}\text { Manufacturin } \\
\text { g round-trip } \\
\text { efficiency }\end{array}$ & $\begin{array}{c}\text { Annual efficiency } \\
\text { loss factor due to } \\
\text { aging }\end{array}$ & $\begin{array}{c}\text { Dis/charge } \\
\text { duration } \\
\text { (hours) }\end{array}$ & $\begin{array}{c}\text { Life } \\
\text { (years) }\end{array}$ & $\begin{array}{c}\text { Base } \\
\text { CAPEX } \\
(\$ / k W h)\end{array}$ \\
\hline $\mathrm{J} 1$ & Li-ion high power & 0.910 & 0.960 & 1 & 8 & 950 \\
\hline $\mathrm{J} 2$ & Li-ion high energy & 0.920 & 0.960 & 2 & 8 & 700 \\
\hline $\mathrm{J} 3$ & Advanced lead acid & 0.800 & 0.960 & 2 & 8 & 900 \\
\hline $\mathrm{J} 4$ & Advanced lead-acid & 0.900 & 0.960 & 5 & 8 & 700 \\
\hline J5 & Valve-regulated lead acid & 0.680 & 0.955 & 2 & 6 & 650 \\
\hline J6 & Valve-regulated lead acid & 0.780 & 0.955 & 4 & 6 & 500 \\
\hline $\mathrm{J} 7$ & Sodium Nickel Chloride & 0.870 & 0.965 & 4 & 10 & 600 \\
\hline J8 & Sodium Sulfur & 0.730 & 0.980 & 7 & 16 & 350 \\
\hline
\end{tabular}

Given the policy sensitivity of feed-in tariff, the company desires to make the investment analysis without consideration of any revenue stream from it (FIT $=0 \mathrm{c} / \mathrm{kWh}$ ). The government is supporting the investment in renewable energy technologies such as PV by offering renewable energy certificates (RECs) as per $\$ / M W h$ generated. The value of RECs is defined by market dynamics, and the company has decided to assume it at $40 \$ / \mathrm{MWh}$. The annual price escalation factor is $3 \%$ with a discount rate of $7 \%$ [77]. The company does not project any change in electricity consumption. With these given factors, the company wants to assess whether it is economically feasible to install PV and/or battery systems. When feasible, the proceeding questions are the specifications of the selected system(s) and the operation mechanism of the system.

We formulated the problem using the model presented in Appendix 1. The problem, consisting of 4,642,931 equations and 5,431,348 variables, was solved for 10 years of operation using CPLEX 12.4.0.1 on a desktop PC with a dual-core 3.2 GHz Intel Xeon processor and $115 \mathrm{~GB}$ RAM. The execution time was 339.204 CPU s. The optimization program suggests that it is more economical to invest in a PV-battery system than to buy electricity completely from the grid. The optimum decision is identified as a $1323.8 \mathrm{~kW}$ PV system with a high-power Li-ion battery of size $\mathrm{j} 1=127.6 \mathrm{kWh}$. This NPV of savings is $\$ 626,760.2$ over ten years with a payback time of 7.2 years. 
According to the optimization results, this integrated PV-battery system will reduce the company's direct dependence on the grid to $70.7 \%$ during the first year of operation. Under this condition, the company receives $4,687,931 \mathrm{kWh}$ of electricity directly from the grid within the first year. The remaining demand is satisfied by the PV system $(1,883,605 \mathrm{kWh}$, i.e., $28.4 \%)$ and battery $(62,164.5 \mathrm{kWh}, 0.9 \%)$.

The PV output over the first year is $2,075,900 \mathrm{kWh}$. It is mainly used for the local load $(92.6 \%)$. The remainder goes to the battery $(3.4 \%)$ or dispatched to the grid (4.0\%). Within the first year, the battery receives $70,698.1 \mathrm{kWh}(83.1 \%)$ of electricity from the PV system, and its remaining charge $(14,388.5 \mathrm{kWh}, 16.9 \%)$ is supplied by the grid, mainly during off-peak periods. The selected $5.5 \mathrm{kWh}$ battery never operates below 15\% SOC and its average annual SOC is $35.9 \%$ (i.e., $45.8 \mathrm{kWh}$ ), over the first year.

In summary, the selected PV-battery system not only reduces the company's energy costs and thus dependence on the grid with a reasonable payback time of 7.2 years, but it also supports the sustainability of the electricity supply chain by reducing the critical peak demand. Figure 8 (A and C) illustrates the company's energy exchange profiles with the grid under the base scenario, without investment in DGS systems (A), and with a PV-battery system (C). It is evident from the comparison of Figure 8A with Figure 8C that with a PV-battery system the values of peak demand incidences have reduced (to below $1100 \mathrm{~kW}$ ) and also negative loads (export or curtail) have appeared. Figure 8 (B and D) illustrates the same annual profiles on a daily basis. The comparison of Figure 8B with Figure 8D clearly shows the impact of the DGS system on demand reduction not only during mid-day but also during the afternoon peak. The average hourly energy import value from the grid (shown with a solid line in the figures) has reduced from $757.3 \mathrm{kWh}$ to $535.1 \mathrm{kWh}$, over the first year. This value is even lower $(526.3$ $\mathrm{kWh}$ ) if the energy exchange average (which also considers export) is considered. 


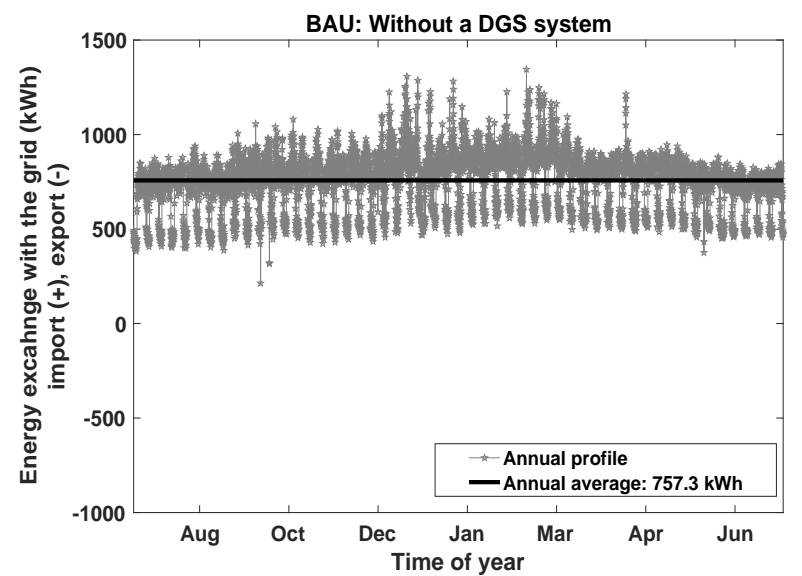

Figure A

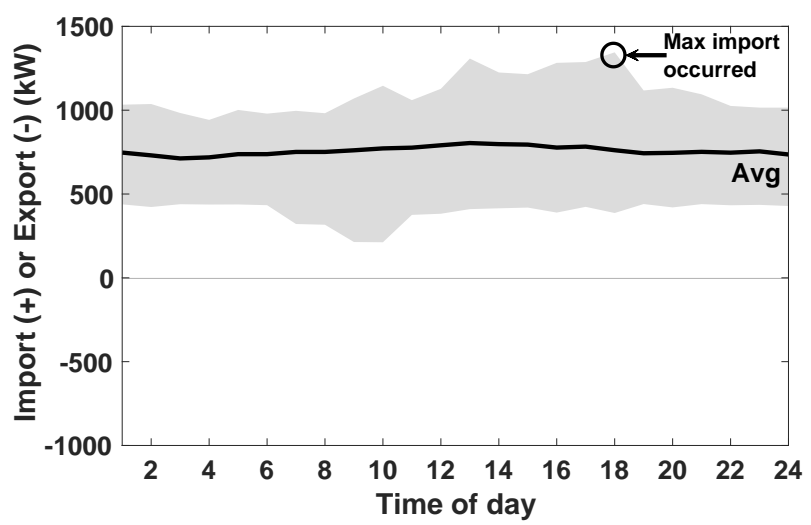

Figure B

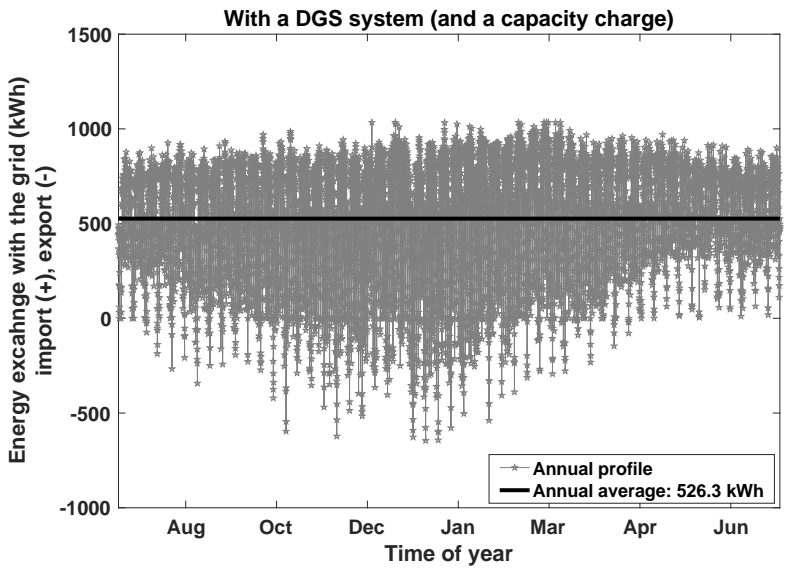

Figure C

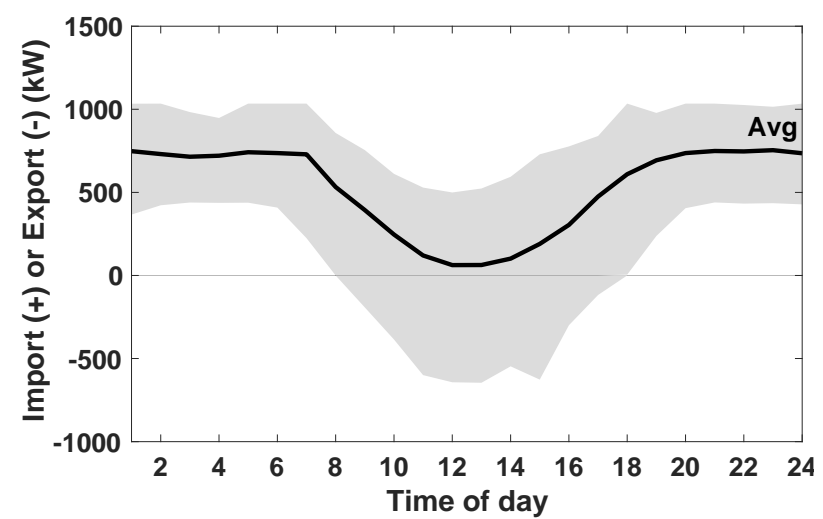

Figure D

Figure 8: The Company's energy exchange profiles at base case (A and B), and with a PV-battery system (C and D); C vs. A and D vs. B show the reduction of peak demand incidences, and also the appearance of negative loads (export or curtail).

Another representation of energy exchange profiles is illustrated in Figure 9 based on the probability of exceedance (POE). This figure clearly shows how the DGS system has successfully reduced the critical peaks occurred at POE $<\sim 3 \%$. Figure 9 also shows that the import from the grid has notably reduced at large POE values (the off-peak or low-demand periods). This implies that at a lower storage price there could be more potential for the installation of a larger storage system. 


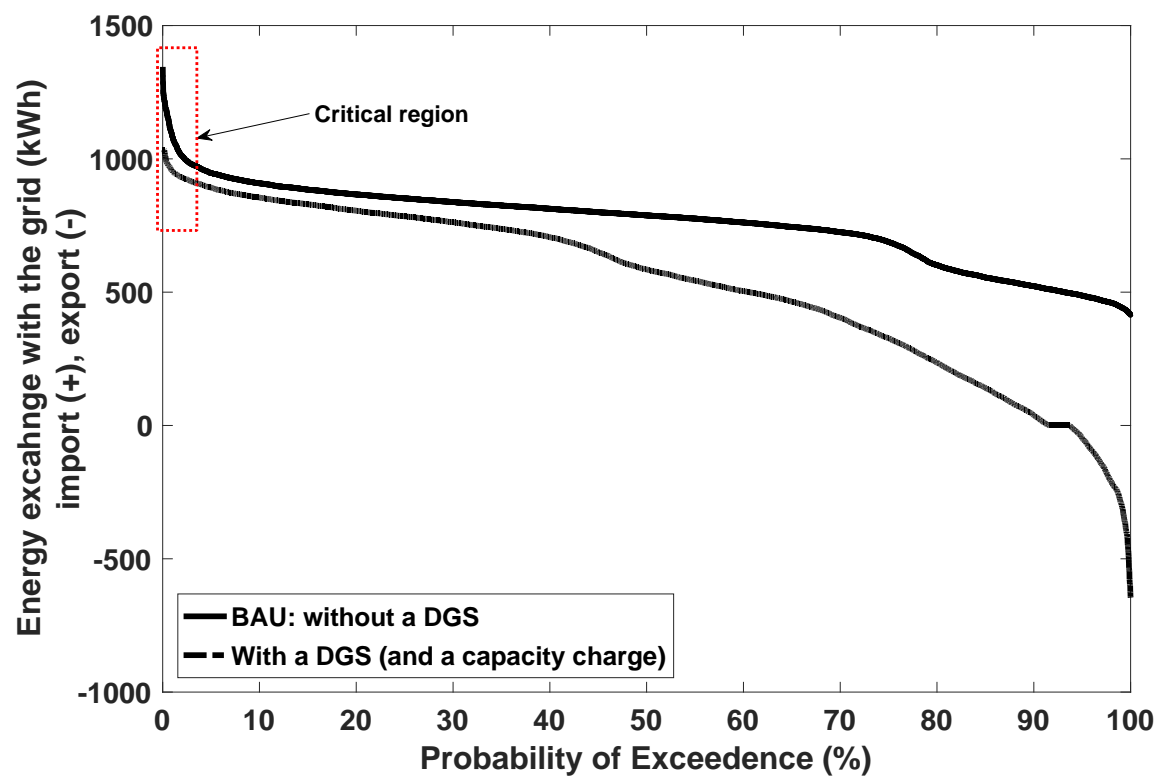

Figure 9: The case-study company's energy exchange profiles based on the probability of exceedance (POE)

In another note, the highest export value (negative in the figure) is $-645.6 \mathrm{~kW}$. This value is still less than the highest import incidence (i.e. 1034.0 kW). However, with reduced PV installation costs and future installations of larger PV systems, there could be conditions that the critical load on the grid reverses from import to export (highest export incidence exceeds that of the highest import). This was the main reason that we introduced a capacity charge for energy export.

The average annual average SOC of the installed battery over the first year is illustrated in Figure 10. It is evident from the figure that the battery makes on average two cycles a day. It charges at night and discharges in the morning before the PV system peaks. During noon and early afternoon, it charges again to support the late afternoon peak demand. 


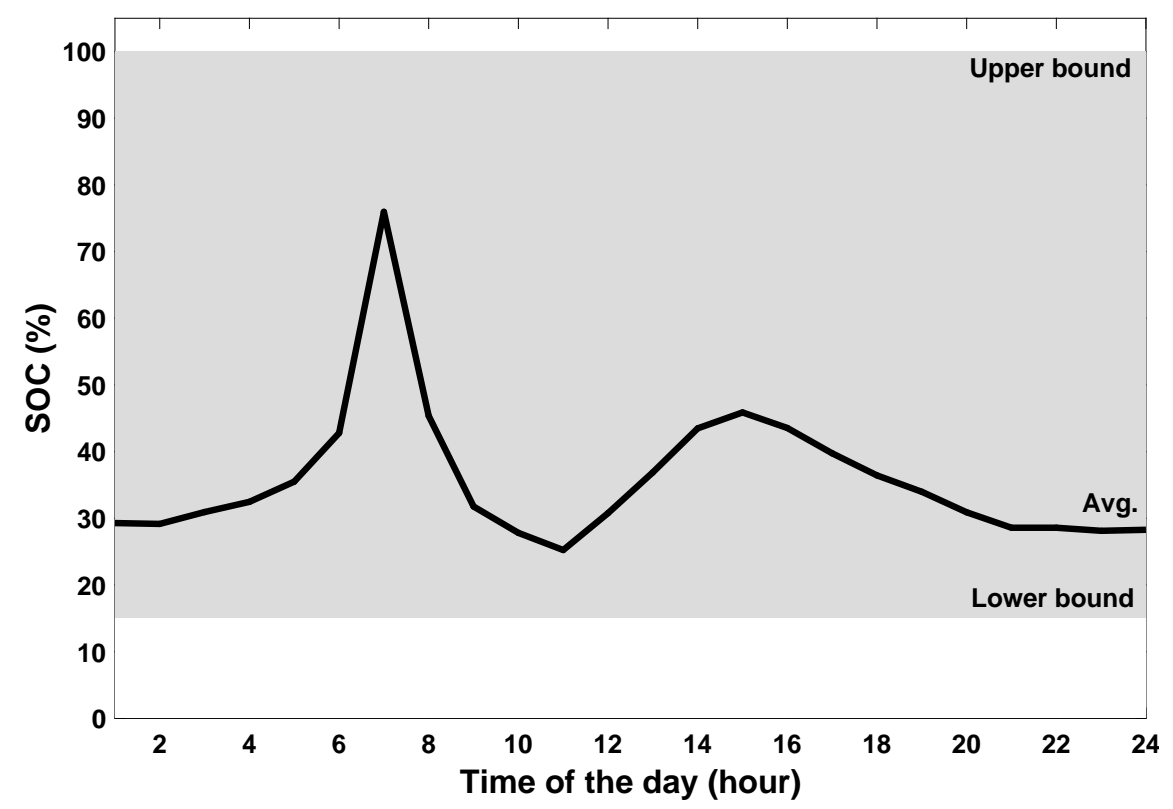

Figure 10: The annual-average daily profile of the company's battery system' SOC during the first year of operation

\subsection{Without a supply charge}

This scenario is similar to the previous example. However, here we would like to assess the impact of the capacity charge on decision-making. For this, we assume that the company receives a new electricity tariff structure as shown in Table 2, but without any capacity charge. The other tariff terms are however multiplied by a factor (in this case 1.237) so that the total annual bill for the base year is unchanged. This means that the off-peak and on-peak tariffs will be $23.7 \%$ higher than the previous scenario, but the capacity charge will be zero. With this modification, the optimization problem, with a similar size of Scenario 1, was executed with a CPU time of $412.5 \mathrm{~s}$.

Under the new condition, the best investment decision is found in installing $1489.0 \mathrm{~kW} \mathrm{PV}$ system (larger than $1323.8 \mathrm{~kW}$ for the previous scenario). The program does not suggest investing in an energy storage system. With this arrangement, the company's NPV of saving is $\$ 858,365.5$ over the first ten years of the PV system operation with the payback time of 6.7 years.

The PV output over the first year is $2,334,935.9 \mathrm{kWh}$. It is mainly used for the local load $(2,122,715.6 \mathrm{kWh}, 90.9 \%)$ and the remainder is exported to the grid $(9.1 \%)$ or curtailed. Overall, this integrated PV system supplies $31.4 \%$ of the load and reduces the company's direct dependence on the grid to $68.6 \%$ during the first year of operation. This value is even better 
than the scenario with capacity charge (70.7\%), but it comes at the cost of a lesser reduction in the critical peak load as evident from Figure 11.

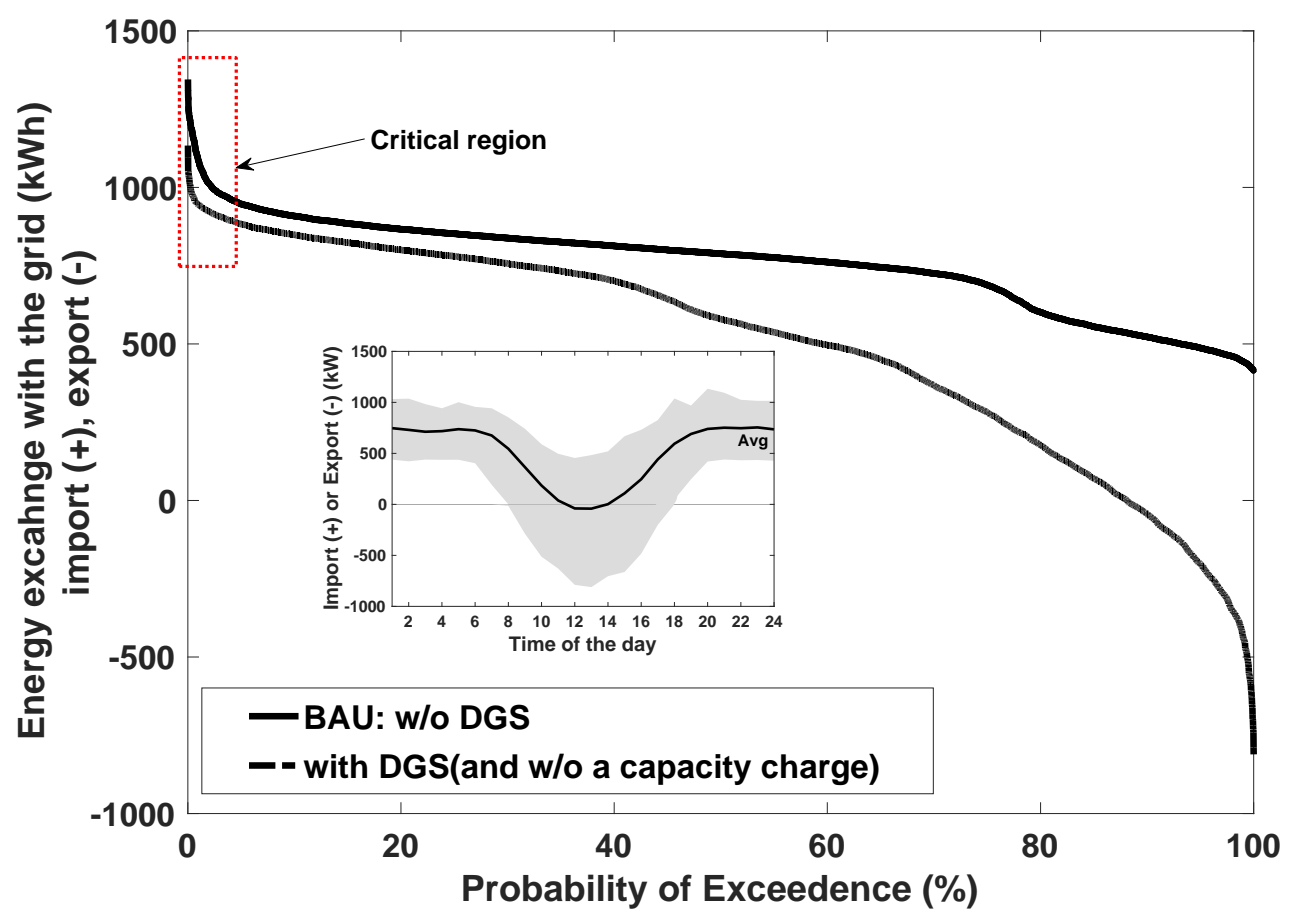

Figure 11: The Company's energy exchange profiles without a capacity charge tariff

The performance comparison of the business as usual (BAU) scenario with the two casestudies, with and without a capacity charge, is provided in Table 4. The business as usual scenarios refer to a company in Melbourne which has paid $\$ 908,158.7$ for its electricity consumption either with a capacity charge and energy tariffs as per Table 2 or without a capacity charge but with $23.7 \%$ extra cost per unit of energy consumed. For each of the given scenarios, the DGS investment model gives the optimal design and provides the optimal operation decisions and scheduling summarized in the last two columns of Table 4.

In summary, the lack of a capacity charge tariff with higher energy rates promotes investment on larger generation systems to curb energy costs. The investment has a relatively better payback-time (6.7 y) with grid dependence reduced to $68.6 \%$. With a capacity charge, these numbers are lower (smaller PV system size and higher grid dependence). Also, the energy cost of the company is higher with the capacity charge. However, the capacity charge promotes the installation of storage systems and thus reduces the peak import and export from the grid better than the scenario without a capacity charge. From a network perspective, with the BAU scenario, the company's critical demand incidence is $1344.8 \mathrm{~kW}$, with high energy tariff, 
without capacity charge this value becomes $1133.4 \mathrm{~kW}$, while with capacity charge, it further declines to 1034.0 , contributing to the improvement in network efficiency. Therefore, one conclusion could be that in a society with energy security issues, avoiding capacity charge can promote investment in larger generation capacity by consumers, however, for societies with peak demand challenges, the capacity charge is seen as an efficient tool to direct the behaviour of consumers towards peak-demand management.

Table 4: Comparison of the business as usual scenario with two DGS investment analyses scenarios: 1) with a capacity charge tariff; 2) Without a capacity charge tariff, but with a higher energy cost

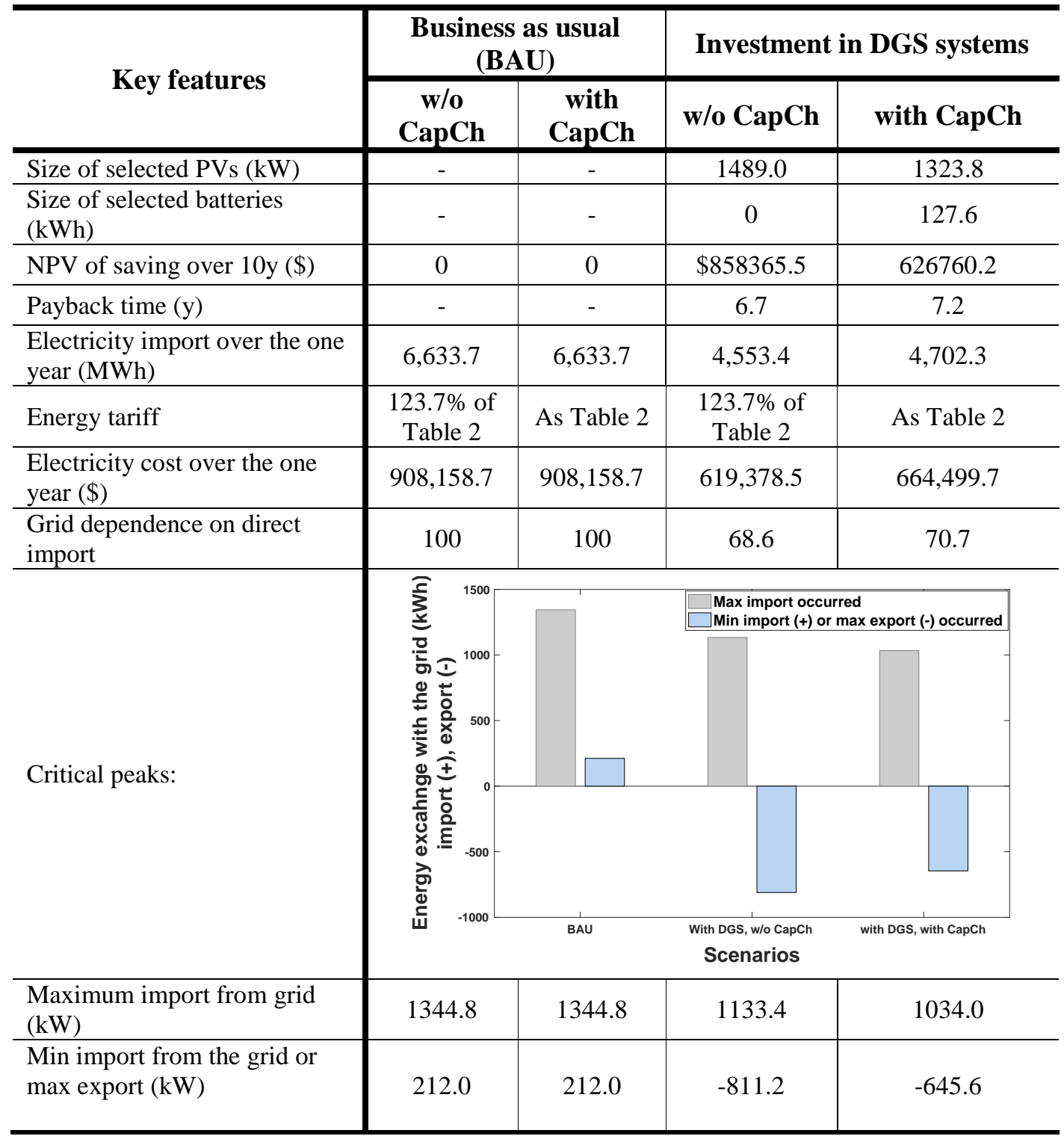




\subsection{Impact of techno-economic parameters}

In the previous two examples, we assessed the impact of capacity charge on the DGS investment decisions. The results clearly showed that capacity charge motivates investment in energy storage. Here, we take the same example with capacity charge (Section 3.1) and investigate the impact of some key techno-economic factors on the investment decisions. We have selected four factors including FIT, RECs, PV price, and battery price. We have considered a few price scenarios for each of the factors, FIT $(\$ / \mathrm{kWh}): 0$ and 0.05 ; REC (\$/MWh): 0, 20, 40, and 60; PV CAPEX (\$/kW): 1000, 1500, and 2000; Battery CAPEX (\$/kWh): 300, 500, 750, and 1000. It is noteworthy that for this analysis we used only one type of battery (j2 in Table 3) with varied CAPEX values. All other parameters are the same as the first case-study (Section 3.1). Combination of two price scenarios for FIT, four scenarios for REC, three scenarios for PV CAPEX, and four scenarios for battery CAPEX gives a total of 96 different problem scenarios. All these optimization problems are executed and their optimal PV size, battery size, and operation schedules, as well as the objective values (NPV of saving over ten years), are obtained. The results are illustrated in Figure 12.

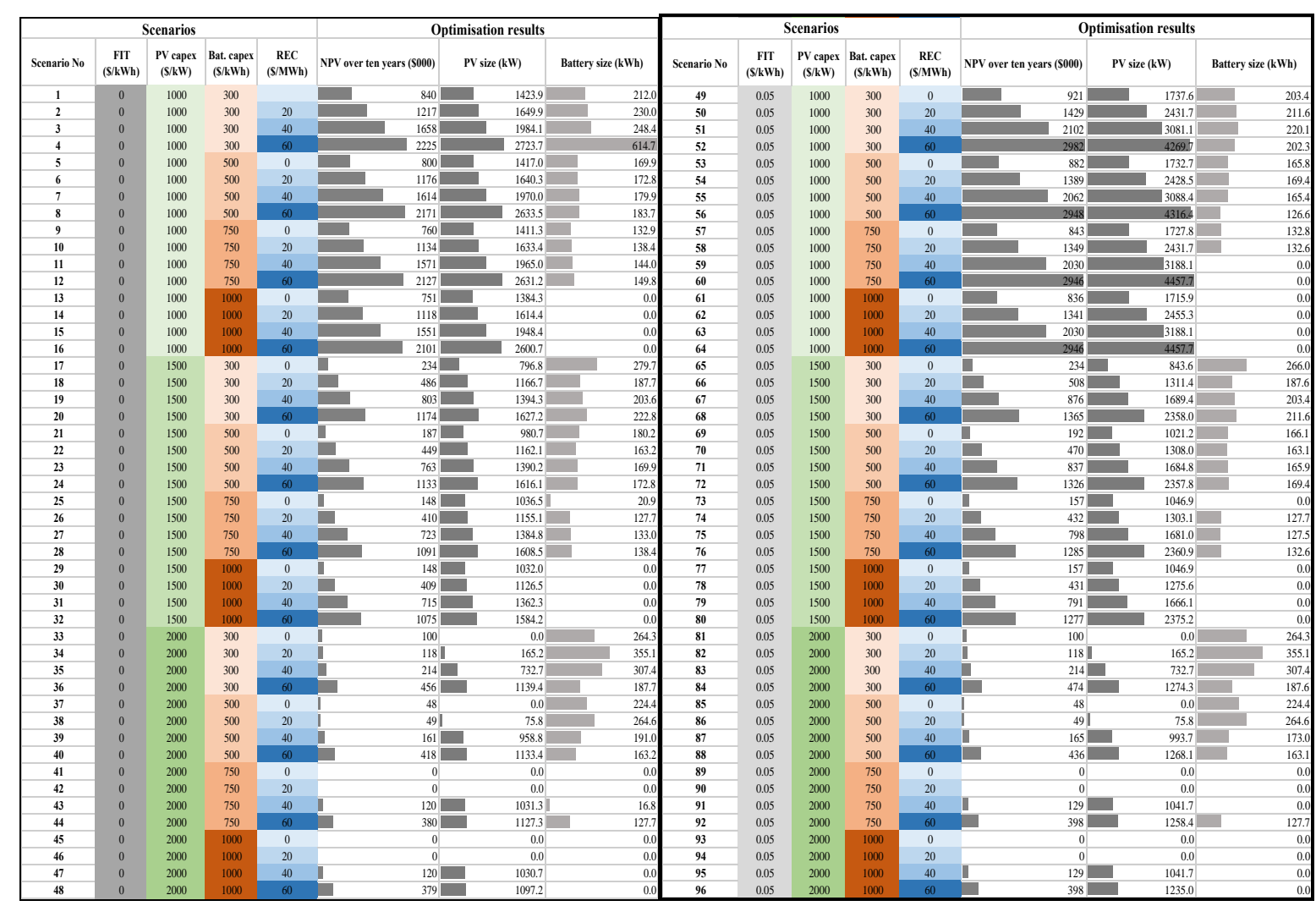

Figure 12: Optimization result summary for 96 scenarios based on four techno-economic factors: FIT (c/kWh): 0 and 5; REC (\$/MWh): 0, 20, 40, and 60; PV CAPEX (\$/kW): 1000, 1500, and 2000; Battery CAPEX (\$/kWh): $300,500,750$, and 1000 . 
According to the results, FIT improves the attractiveness of investment in DGS systems and the optimal size of PV increases across all scenarios. However, the introduction of FIT motivates the direct export of surplus energy and reduces the urgency of battery storage installation. For instance, while on average the 48 scenarios with FIT $=0$ require $139.1 \mathrm{kWh}$ battery, this value reduces to $119.1 \mathrm{kWh}$ with a FIT $=0.05 \$ / \mathrm{kWh}$.

The price of PV shows a strong impact on the optimal size of PV and the NPV. The average size of PV across 32 scenarios with PV CAPEX of $1000 \$ / \mathrm{kW}$ is $2417 \mathrm{~kW}$. At $1500 \$ / \mathrm{kW}$, this value is $1430 \mathrm{~kW}$ (>40\% drop). For the remaining 32 scenarios with PV CAPEX of $2000 \$ / \mathrm{kW}$, this value becomes notably low, $549 \mathrm{~kW}$, which is almost one-fifth of the scenarios with PV CAPEX of $1000 \$ / \mathrm{kW}$. The NPV of savings also drops with the reduction in the PV size. However, the PV price does not show an evident impact on battery size. Likewise, battery CAPEX does not reveal any correlation with the optimal PV size. The battery CAPEX is the most influential factor in its optimal size. With battery CAPEX of $1000 \$ / \mathrm{kWh}$, none of the 24 scenarios selects any battery. With the CAPEX of $750 \$ / \mathrm{kWh}$, the average battery size becomes $79.6 \mathrm{kWh}$. With the CAPEX of $500 \$ / \mathrm{kWh}$, this value increases with more than two-fold (181.4 $\mathrm{kWh}$ ). At battery CAPEX of $300 \$ / \mathrm{kWh}$, the average battery size reaches $255.6 \mathrm{kWh}$.

The results clearly show that that FIT and REC are effective policies for motivating the investment in DGS systems. However, as both REC and FIT are renewable energy generation incentives, they motivate investment in generation (here PV) quantity and cannot tackle the prosumers' peak-management. As such, we observe in Figure 12 their significant impact on optimal PV size and a negligible impact on battery size. The FIT even reduces the attractiveness of battery storage. Therefore, from DSM policy-making perspective, a tailored combination of REC, FIT, and the capacity charge is needed for encouraging both investments in renewable energy and load shifting technologies.

\section{Conclusions}

Tariff design is one of the most critical tools for demand-side management (DSM) and for shaping consumer behaviour. With recent price reduction in distributed generation and storage (DGS) systems, interest has increased in devising policies for directing the consumers' behaviour towards using DGS systems in line with DSM objectives. This has further increased the complexity of tariff modelling. On the one hand, a smart tariff structure is required to reflect the economic value of a DGS system for its owner and thus promote widespread DGS uptake. On the other hand, it should satisfy the key DSM goals such as peak load reduction. The current tariff mechanisms such as time-of-use and inclining blocks, though effective tools, cannot 
guarantee peak load reduction. As we discussed in Section 3.3, renewable energy subsidies in the form of REC or FIT, though efficient for investment in generation technology, cannot lead to peak load reduction.

While ToU and inclining block tariffs, as well as renewable energy subsidies, have received decent attention as successful policies, there is another less-discussed efficient tariff known as rollover network capacity charge. It is a penalty for the highest recorded power usage over the previous reading cycle (or year). We anticipated that the consideration of capacity charge might improve the economic feasibility of energy storage and thus motivate its demand-side uptake. To investigate this, we integrated rollover network capacity charge into DGS system sizing and scheduling.

We executed some scenarios with and without a capacity charge. The results showed that high energy rates promote investment in larger PV generation systems to curb energy costs. The investment has a relatively better payback-time and less grid dependence. With lower energy rates but with the introduction of the capacity charge, these numbers are slightly lower (smaller PV system size and higher grid dependence). Also, the energy cost of the peak-user is higher with the capacity charge. However, it promotes the installation of storage systems and thus reduces the peak import and export from the grid more efficient than the scenario without a capacity charge. The results lead us to the following key conclusions.

\section{- Effective energy-justice mechanism}

Capacity charge transfers the network over-investment costs to the critical-peak users by enforcing them to pay extra for their critical peak consumption. This gives an incentive to invest in DSM systems, such as energy storage, to shift or reduce their peak import from the grid. However, reducing the consumption or changing the consumption pattern is not always possible and making new investments in DGS systems is preferred. With falling PV and battery costs, DGS systems are becoming more attractive to energy users. However, a strong DSM policy with the capacity charge induces customers to make investments in demand-side management earlier. This is particularly important for electricity networks that are facing peak demand challenges already today. Therefore, this is a fair mechanism which enforces those 
who contribute more to critical peak loads to take more responsibility in addressing the problem.

\section{- Addressing the challenges of new peaks}

One of the big concerns in the power systems is a possibility of new peak demands in the future [3]. The capacity charge not only can curb the current afternoon peak loads but can also avoid any unconventional new peaks in the future. It can even address the possible challenges of sharp changes in load profiles during the moments when the ToU tariff shifts from one price threshold to another. There are at least two new peaks anticipated for the future. One such new peak pertains to mid-day solar power export. As the probability of exceedance (POE) curves (e.g., Figure 9) show, the significant ratio of PV generation occurs in low demand periods (high POEs), e.g., sunny mid-day. With widespread PV uptake, there is a risk of voltage and frequency failure due to over-export to the network. Consideration of capacity charge can also curb export (As the example in Section 3.2 showed) and motivate shifting the export time by energy storage or any other mechanism. The other new peak is related to energy import at times known traditionally as off-peak periods. The continuous decline in battery prices and the consequent widespread uptake of stationary or EV batteries may encourage consumers to arrange the charging time of their appliances at currently known off-peak periods (with lower electricity tariff) which may lead to new peak demands. The capacity charge appears as an effective mechanism to curb any form of new peaks including the mentioned ones. In conclusion, from the DSM policy-making perspective, a tailored combination of renewable energy certificates, energy tariffs, and a capacity charge is needed for encouraging both investments in renewable energy and load management. 


\section{Appendix 1}

Table 5: The formulation of a decision support program for DGS system screening, selection, sizing, and scheduling with inclusion of capacity charge tariff

\begin{tabular}{|c|c|c|}
\hline Formula & Formula description & Note \\
\hline$\sum_{i=1}^{I} y_{i} \leq N^{D G}$ & $\begin{array}{l}\text { Limit on the number of selected DG } \\
\text { systems }\end{array}$ & $y_{i}= \begin{cases}1, & \text { if DG system } i \text { is selected } \\
0, & \text { otherwise }\end{cases}$ \\
\hline$\sum_{j=1}^{J} y_{j}^{\prime} \leq N^{S}$ & $\begin{array}{l}\text { Limit on the number of selected storage } \\
\text { systems }\end{array}$ & $y_{j}^{\prime}= \begin{cases}1, & \text { if storage system } j \text { is selected } \\
0, & \text { otherwise }\end{cases}$ \\
\hline$\sum_{i=1}^{I} y_{i} A_{i}+\sum_{j=1}^{J} y_{j}^{\prime} A_{j} \leq A^{m}$ & $\begin{array}{l}\text { Limit on the total area occupied by the } \\
\text { DGS system }\end{array}$ & Total area limit: $A^{m}$ \\
\hline$\sum_{i=1}^{I} y_{i} V_{i}+\sum_{j=1}^{J} y_{j}^{\prime} V_{j} \leq V^{m}$ & $\begin{array}{l}\text { Limit on the total volume occupied by } \\
\text { the DGS system }\end{array}$ & Total volume limit: $V^{m}$ \\
\hline$F C_{i p}=X_{i p}^{D G} F_{i p} / \eta_{i p}^{D G}$ & Feed supply cost of DG unit $i$ at period $p$ & $\begin{array}{l}F_{i p}: \text { Feed price per unit supply for DG unit } i \text { at period } p \\
X_{i p}^{D G}: \text { Total generation of DG unit } i \text { at period } p \\
\eta_{i p}^{D G}: \text { Efficiency of DG unit } i \text { at period } p\end{array}$ \\
\hline$E_{i p}=X_{i p}^{D G} C I_{i p} / \eta_{i p}^{D G}$ & $\begin{array}{l}\mathrm{CO}_{2} \text {-equivalent } \mathrm{GHG} \text { emission from } \mathrm{DG} \\
i \text { at period } p\end{array}$ & $\begin{array}{l}C I_{i p} \text { : Carbon intensity of DG unit } i \text { per unit of feed energy } \\
\text { at period } p\end{array}$ \\
\hline$G H C_{i p}=E_{i p} C P_{p}$ & Incurred GHG cost for DG $i$ at period $p$ & $C P_{p:} \mathrm{CO}_{2}$-equivalent $\mathrm{GHG}$ emission penalty at period $p$ \\
\hline$X_{i p}^{D G}=X_{i p}^{D G . G}+X_{i p}^{D G . L}+\sum_{j=1}^{J} X_{i j p}^{D G . S} \leq y_{i} C_{i p}^{D G}$ & $\begin{array}{l}\text { Limit on the total energy production } \\
\text { from DG } i \text { at period } p\end{array}$ & $\begin{array}{l}C_{i p}^{D G}: \text { The maximum "generatable" capacity of a DG unit } i \\
\text { at period } p \\
X_{\text {nip }}^{D G . N}: \text { Export from DG } i \text { to network } n \text { at period } p \\
X_{\text {kip }}^{D G . K}: \text { Supply from DG } i \text { to load } k \text { at period } p \\
X_{i j p}^{D G . S}: \text { Supply from DG } i \text { to storage } j \text { at period } p\end{array}$ \\
\hline$X_{p}^{G . L}+\sum_{i=1}^{I} \eta_{i p}^{D G i n} X_{i p}^{D G . L}+\sum_{j=1}^{J} X_{j p}^{S . L} \leq L_{p}$ & Local load limit in any period $p$ & $\begin{array}{l}X_{p}^{G . L}: \text { Supply from grid to load at period } p \\
L_{p}: \text { demand during period } p \\
X_{i p}^{D G . L}: \text { Supply from DG } i \text { to load at period } p \\
X_{j p}^{S . L}: \text { Supply from storage } j \text { to load at period } p\end{array}$ \\
\hline
\end{tabular}




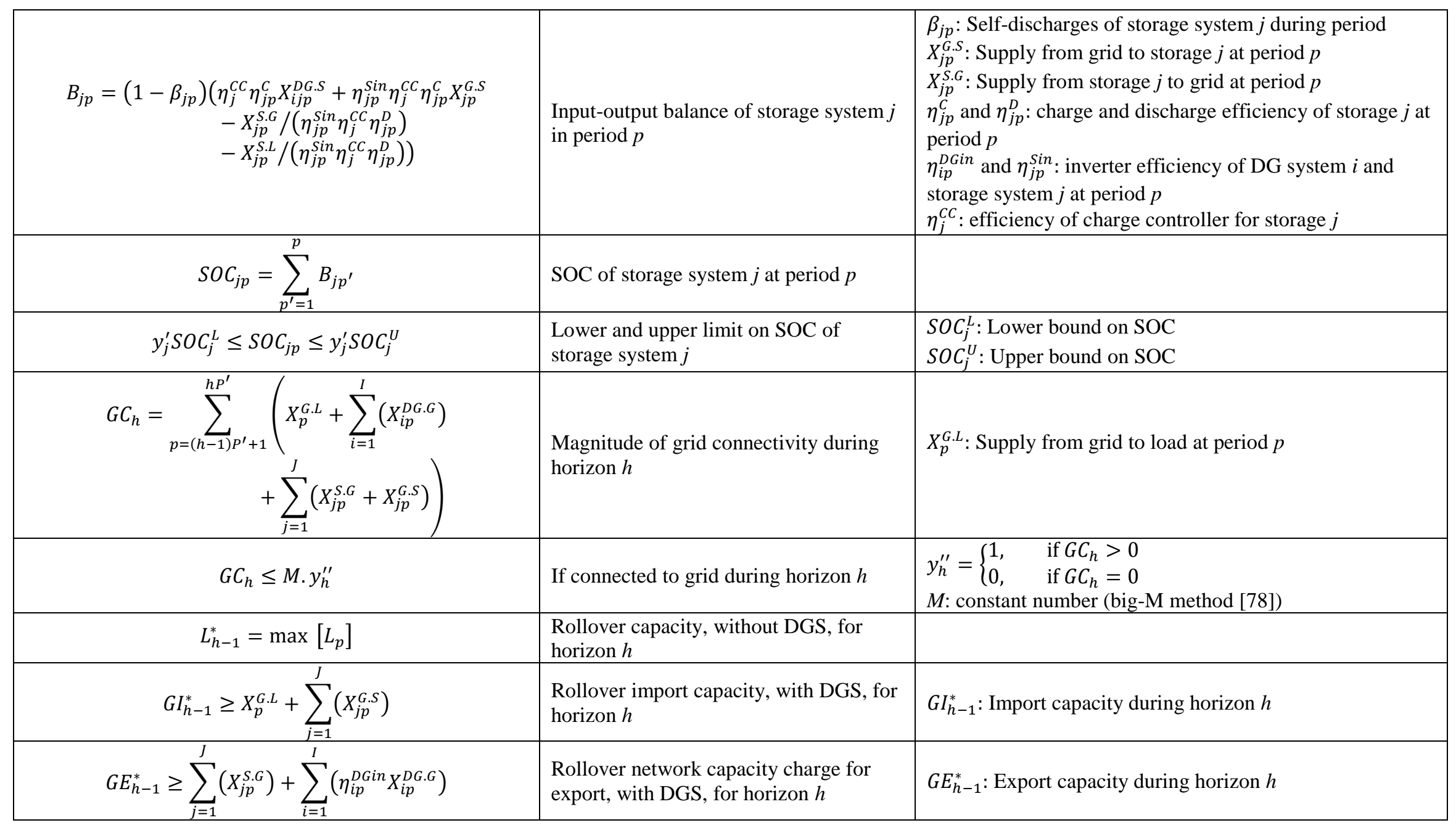




\begin{tabular}{|c|c|c|}
\hline 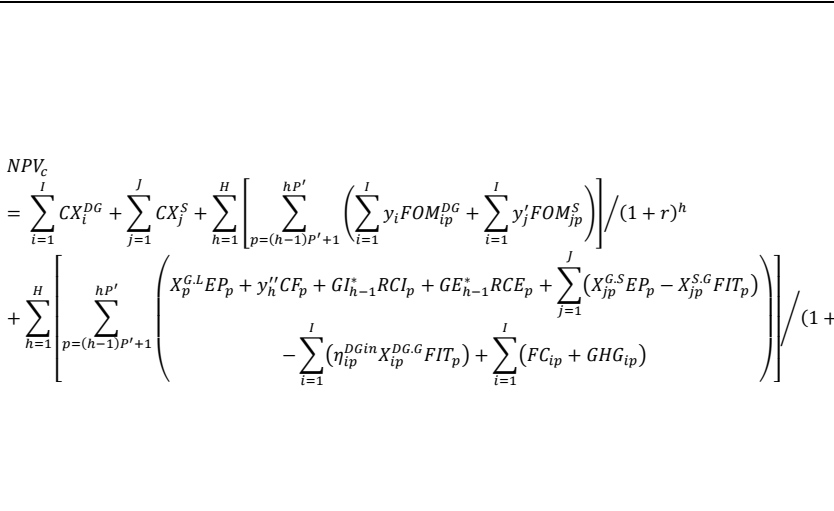 & $\begin{array}{l}\text { Objective function for the net present } \\
\text { value of costs }\end{array}$ & $\begin{array}{l}r: \text { Discount rate over } h \\
F O M_{i p}^{D G} \text { and } F O M_{j p}^{S}: \text { FOM of DG system } i \text { and storage } \\
\text { system } j \text { at period } p \\
C X_{i}^{D G} \text { and } C X_{j}^{S}: \text { Installation cost of DG system } i \text { and } \\
\text { storage system } j \\
E P_{p}: \text { electricity price at period } p \\
C F_{p}: \text { Connection fee (or supply charge) at period } p \\
R C I_{p}: \text { Rollover network capacity charge for import at } \\
\text { period p. } \\
R C E_{p}: \text { Rollover network capacity charge for export at } \\
\text { period p. } \\
F i T_{p}: \text { Feed-in-tariff during period } p\end{array}$ \\
\hline $\begin{array}{l}N P V_{S} \\
=\sum_{h=1}^{H}\left[\sum_{p=(h-1) P^{\prime}+1}^{h P^{\prime}}\left(L_{p} E P_{p}+C F_{p}+L_{h-1}^{*} R C_{p}\right)\right] /(1+r)^{h} \\
-N P V_{c}\end{array}$ & $\begin{array}{l}\text { Objective function for the net present } \\
\text { value of savings }\end{array}$ & \\
\hline
\end{tabular}




\section{List of Abbreviations}

CAPEX capital expenditure

CPD critical peak demand

CDF cumulative distribution functions

CHP combined heat and power

DER distributed [renewable] energy resources

DG distributed generation

DGS distributed generation and storage (Here DGS means: "distributed generation, or storage, or both")

DOD depth of discharge

DSM demand-side management

EES Electrical energy storage

EV electric vehicle

FIT feed in tariff

FOM fixed operation and maintenance cost

GHG greenhouse gas

GST goods and service tax

GW gigawatt

GHI global horizontal irradiation

LPSP loss of power supply probability

MILP mixed-integer linear program

MINLP mixed-integer nonlinear program

NPV net present value

NRLP Newton-Raphson linear programming

NTGA non-dominated sorting genetic algorithm

NSW New South Wales

OCL operational charge limit

OPEX operational expenditure

PCA principal component analysis

POE probability of exceedance

PR performance ratio 


$\begin{array}{ll}\text { PV } & \text { photovoltaic } \\ \text { REC } & \text { renewable energy certificate } \\ \text { SOC } & \text { state of charge } \\ \text { ToU } & \text { time-of-use } \\ \text { LLP } & \text { loss of load probability } \\ \text { UN } & \text { United Nations }\end{array}$

\section{References}

[1] Billinton R. Power System Reliability Evaluation: Gordon and Breach; 1970.

[2] Strbac G. Demand side management: Benefits and challenges. Energy Policy. 2008;36:441926.

[3] Productivity-Commission. Productivity Commission Reports No. 62 Electricity Network Regulatory Frameworks Volume 1. Productivity Commission Reports. Melbourne, Australia: Productivity Commission; 2013.

[4] Khalilpour R, Vassallo A. Community Energy Networks With Storage: Modeling Frameworks for Distributed Generation. Singapore: Springer; 2016.

[5] Chen Y, Xu P, Gu J, Schmidt F, Li W. Measures to improve energy demand flexibility in buildings for demand response (DR): A review. Energy and Buildings. 2018;177:125-39.

[6] Davito B, Tai H, Uhlander R. The smart grid and the promise of demand-side management. McKinsey and Company; 2010.

[7] Pierpoint LM. Harnessing electricity storage for systems with intermittent sources of power: Policy and R\&D needs. Energ Policy. 2016;96:751-7.

[8] Yang C, Meng C, Zhou K. Residential electricity pricing in China: The context of price-based demand response. Renewable and Sustainable Energy Reviews. 2018;81:2870-8.

[9] Allcott H. The smart grid, entry, and imperfect competition in electricity markets. National Bureau of Economic Research; 2012.

[10] ENA. Towards a National Approach to Electricity Network Tariff Reform. ENA Position Paper: Energy Networks Association; 2014.

[11] Steriotis K, Tsaousoglou G, Efthymiopoulos N, Makris P, Varvarigos E. A novel behavioral real time pricing scheme for the active energy consumers' participation in emerging flexibility markets. Sustainable Energy, Grids and Networks. 2018;16:14-27.

[12] Simshauser P. Price discrimination and the modes of failure in deregulated retail electricity markets. Energy Economics. 2018;75:54-70.

[13] Waterson M. The characteristics of electricity storage, renewables and markets. Energ Policy. 2017;104:466-73.

[14] Fikru MG, Gelles G, Ichim A-M, Kimball JW, Smith JD, Zawodniok MJ. An economic model for residential energy consumption, generation, storage and reliance on cleaner energy. Renewable Energy. 2018;119:429-38.

[15] Byrne J, Taminiau J. A review of sustainable energy utility and energy service utility concepts and applications: realizing ecological and social sustainability with a community utility. WIREs Energy and Environment. 2016;5:136-54. 
[16] Bryant ST, Straker K, Wrigley C. The typologies of power: Energy utility business models in an increasingly renewable sector. Journal of Cleaner Production. 2018;195:1032-46.

[17] Martin N, Rice J. Solar Feed-In Tariffs: Examining fair and reasonable retail rates using cost avoidance estimates. Energy Policy. 2018;112:19-28.

[18] Li Y, Gao W, Ruan Y, Ushifusa Y. Demand response of customers in Kitakyushu smart community project to critical peak pricing of electricity. Energy and Buildings. 2018;168:251-60. [19] Zhang Y, Augenbroe G. Optimal demand charge reduction for commercial buildings through a combination of efficiency and flexibility measures. Applied Energy. 2018;221:180-94.

[20] Passey R, Haghdadi N, Bruce A, MacGill I. Designing more cost reflective electricity network tariffs with demand charges. Energy Policy. 2017;109:642-9.

[21] Fridgen G, Kahlen M, Ketter W, Rieger A, Thimmel M. One rate does not fit all: An empirical analysis of electricity tariffs for residential microgrids. Applied Energy. 2018;210:800-14.

[22] Young S, Bruce A, MacGill I. Potential impacts of residential PV and battery storage on Australia's electricity networks under different tariffs. Energy Policy. 2019;128:616-27.

[23] van der Stelt S, AlSkaif T, van Sark W. Techno-economic analysis of household and community energy storage for residential prosumers with smart appliances. Applied Energy. 2018;209:266-76.

[24] Eid C, Koliou E, Valles M, Reneses J, Hakvoort R. Time-based pricing and electricity demand response: Existing barriers and next steps. Utilities Policy. 2016;40:15-25.

[25] Hakvoort R, Koliou E. Energy management and demand side response. Energy Science and Technology Studium Press LLC. 2014.

[26] Yamegueu D, Azoumah Y, Py X, Zongo N. Experimental study of electricity generation by Solar PV/diesel hybrid systems without battery storage for off-grid areas. Renewable Energy. 2011;36:1780-7.

[27] Anwar A, Béguery P, Pflaum P, Huynh J, Friedman J. Optimal DER Sizing Using Microgrid Design Tool Integrating Model Predictive Control Based Energy Management - A Case Study. 2018 IEEE Energy Conversion Congress and Exposition (ECCE)2018. p. 3799-806.

[28] Nema P, Nema RK, Rangnekar S. A current and future state of art development of hybrid energy system using wind and PV-solar: A review. Renewable and Sustainable Energy Reviews. 2009;13:2096-103.

[29] McGowan JG, Manwell JF. Hybrid wind/PV/diesel system experiences. Renewable Energy. 1999;16:928-33.

[30] Merei G, Berger C, Sauer DU. Optimization of an off-grid hybrid PV-Wind-Diesel system with different battery technologies using genetic algorithm. Solar Energy. 2013;97:460-73.

[31] Dufo-López R, Bernal-Agustín JL. Multi-objective design of PV-wind-diesel-hydrogenbattery systems. Renewable Energy. 2008;33:2559-72.

[32] Neves D, Silva CA, Connors S. Design and implementation of hybrid renewable energy systems on micro-communities: A review on case studies. Renewable and Sustainable Energy Reviews. 2014;31:935-46.

[33] Gordon JM. Optimal Sizing of Stand-Alone Photovoltaic Solar Power-Systems. Solar Cells. 1987;20:295-313.

[34] Egido M, Lorenzo E. The Sizing of Stand Alone Pv-Systems - a Review and a Proposed New Method. Solar Energy Materials and Solar Cells. 1992;26:51-69.

[35] Lorenzo E, Narvarte L. On the usefulness of stand-alone PV sizing methods. Progress in Photovoltaics. 2000;8:391-409. 
[36] Fragaki A, Markvart T. Stand-alone PV system design: Results using a new sizing approach. Renewable Energy. 2008;33:162-7.

[37] Peippo K, Lund PD. Optimal Sizing of Grid-Connected Pv-Systems for Different Climates and Array Orientations - a Simulation Study. Solar Energy Materials and Solar Cells. 1994;35:44551.

[38] Lu B, Shahidehpour M. Short-term scheduling of battery in a grid-connected PV/battery system. Power Systems, IEEE Transactions on. 2005;20:1053-61.

[39] Kaushika ND, Gautam NK, Kaushik K. Simulation model for sizing of stand-alone solar PV system with interconnected array. Solar Energy Materials and Solar Cells. 2005;85:499-519.

[40] Pham C-T, Månsson D. Optimal energy storage sizing using equivalent circuit modelling for prosumer applications (Part II). Journal of Energy Storage. 2018;18:1-15.

[41] Hesse CH, Martins R, Musilek P, Naumann M, Truong NC, Jossen A. Economic Optimization of Component Sizing for Residential Battery Storage Systems. Energies. 2017;10.

[42] Mellit A, Kalogirou SA, Hontoria L, Shaari S. Artificial intelligence techniques for sizing photovoltaic systems: A review. Renewable \& Sustainable Energy Reviews. 2009;13:406-19.

[43] Cheng Y-S, Liu Y-H, Hesse CH, Naumann M, Truong NC, Jossen A. A PSO-Optimized Fuzzy Logic Control-Based Charging Method for Individual Household Battery Storage Systems within a Community. Energies. 2018;11.

[44] Hemmati R, Saboori H. Stochastic optimal battery storage sizing and scheduling in home energy management systems equipped with solar photovoltaic panels. Energy and Buildings. 2017;152:290-300.

[45] Riffonneau Y, Bacha S, Barruel F, Ploix S. Optimal Power Flow Management for Grid Connected PV Systems With Batteries. Ieee Transactions on Sustainable Energy. 2011;2:309-20. [46] Yu R, Kleissl J, Martinez S. Storage Size Determination for Grid-Connected Photovoltaic Systems. Sustainable Energy, IEEE Transactions on. 2013;4:68-81.

[47] Ratnam EL, Weller SR, Kellett CM. An optimization-based approach for assessing the benefits of residential battery storage in conjunction with solar PV. Bulk Power System Dynamics and Control - IX Optimization, Security and Control of the Emerging Power Grid (IREP), 2013 IREP Symposium2013. p. 1-8.

[48] Halliday J, Markvart T, Ross JN. Battery management for PV systems. Power Engineer. 2003;17:46-.

[49] Zhong Q, Khalilpour R, Vassallo A, Sun Y. A logic-based geometrical model for the next day operation of PV-battery systems. Journal of Energy Storage. 2016;7:181-94.

[50] Khalilpour KR, Vassallo A. Technoeconomic parametric analysis of PV-battery systems. Renewable Energy. 2016;97:757-68.

[51] Appelbaum J, Braunstein A, Bani J. Performance analysis of a solar-electrical system with a load and storage batteries. Energy Conversion. 1977;16:105-10.

[52] Fragaki A, Markvart T. System memory effects in the sizing of stand-alone PV systems. Progress in Photovoltaics. 2013;21:724-35.

[53] Pedram M, Chang N, Kim Y, Wang Y. Hybrid electrical energy storage systems. Proceedings of the 16th ACM/IEEE international symposium on Low power electronics and design. Austin, Texas, USA: ACM; 2010. p. 363-8.

[54] Stadler M, Groissböck M, Cardoso G, Marnay C. Optimizing Distributed Energy Resources and building retrofits with the strategic DER-CAModel. Applied Energy. 2014;132:557-67. 
[55] Mashayekh S, Stadler M, Cardoso G, Heleno M. A mixed integer linear programming approach for optimal DER portfolio, sizing, and placement in multi-energy microgrids. Applied Energy. 2017;187:154-68.

[56] Wang Y, Lin X, Pedram M, Park S, Chang N. Optimal control of a grid-connected hybrid electrical energy storage system for homes. Design, Automation \& Test in Europe Conference \& Exhibition (DATE), 20132013. p. 881-6.

[57] Kim Y, Park S, Chang N, Xie Q, Wang YZ, Pedram M. Networked Architecture for Hybrid Electrical Energy Storage Systems. 2012 49th Acm/Edac/Ieee Design Automation Conference (Dac). 2012:522-8.

[58] Kim Y, Park S, Wang YZ, Xie Q, Chang NY, Poncino M, et al. Balanced Reconfiguration of Storage Banks in a Hybrid Electrical Energy Storage System. 2011 Ieee/Acm International Conference on Computer-Aided Design (Iccad). 2011:624-31.

[59] Xie Q, Wang YZ, Kim Y, Pedram M, Chang N. Charge Allocation in Hybrid Electrical Energy Storage Systems. Ieee Transactions on Computer-Aided Design of Integrated Circuits and Systems. 2013;32:1003-16.

[60] Xie Q, Wang YZ, Pedram M, Kim Y, Shin D, Chang N. Charge Replacement in Hybrid Electrical Energy Storage Systems. 2012 17th Asia and South Pacific Design Automation Conference (Asp-Dac). 2012:627-32.

[61] Manshadi SD, Khodayar ME. Resilient Operation of Multiple Energy Carrier Microgrids. Ieee T Smart Grid. 2015;6:2283-92.

[62] Abdulla K, Hoog JD, Muenzel V, Suits F, Steer K, Wirth A, et al. Optimal Operation of Energy Storage Systems Considering Forecasts and Battery Degradation. Ieee T Smart Grid. 2017;PP:1-.

[63] Khalilpour R, Vassallo A. Planning and operation scheduling of PV-battery systems: A novel methodology. Renewable and Sustainable Energy Reviews. 2016;53:194-208.

[64] Novoa L, Flores R, Brouwer J. Optimal renewable generation and battery storage sizing and siting considering local transformer limits. Applied Energy. 2019;256:113926.

[65] Alsaidan I, Alanazi A, Gao W, Wu H, Khodaei A. State-Of-The-Art in Microgrid-Integrated Distributed Energy Storage Sizing. Energies. 2017;10:1421.

[66] Atia R, Yamada N. Distributed Renewable Generation and Storage System Sizing Based on Smart Dispatch of Microgrids. Energies. 2016;9:176.

[67] Xiang Y, Han W, Zhang J, Liu J, Liu Y. Optimal Sizing of Energy Storage System in Active Distribution Networks Using Fourier-Legendre Series Based State of Energy Function. IEEE Transactions on Power Systems. 2018;33:2313-5.

[68] ElNozahy MS, Abdel-Galil TK, Salama MMA. Probabilistic ESS sizing and scheduling for improved integration of PHEVs and PV systems in residential distribution systems. Electr Pow Syst Res. 2015;125:55-66.

[69] Bai M, Tang W, Cong P, Wu C, Zhang X, Zhang L, et al. Locating and sizing of photovoltaic generation and energy storage in active distribution network based on virtual partition. 2015 IEEE PES Asia-Pacific Power and Energy Engineering Conference (APPEEC)2015. p. 1-5.

[70] Umeozor EC, Trifkovic M. Operational scheduling of microgrids via parametric programming. Appl Energ. 2016;180:672-81.

[71] Zhou N, Liu N, Zhang J, Lei J. Multi-Objective Optimal Sizing for Battery Storage of PVBased Microgrid with Demand Response. Energies. 2016;9:591.

[72] Alipour M, Mohammadi-Ivatloo B, Zare K. Stochastic Scheduling of Renewable and CHPBased Microgrids. Ieee T Ind Inform. 2015;11:1049-58. 
[73] Xie P, Cai Z, Liu P, Li X, Zhang Y. Optimal Sizing of Energy Storage for Microgrid Systems Considering Energy Balance Ability Indicator. 2018 International Conference on Power System Technology (POWERCON)2018. p. 1390-6.

[74] Pandžić H. Optimal battery energy storage investment in buildings. Energy and Buildings. 2018;175:189-98.

[75] Wang Y, Yi Z, Shi D, Yu Z, Huang B, Wang Z. Optimal Distributed Energy Resources Sizing for Commercial Building Hybrid Microgrids. 2018 IEEE Power \& Energy Society General Meeting (PESGM)2018. p. 1-5.

[76] KEMA-Sandia. ES-Select ${ }^{\mathrm{TM}}$ Documentation and User's Manual-Version 2.0. In: Nourai A, editor.: Sandia National Laboratories; 2012.

[77] Summers VM, Wimer JG. QGESS: Cost Estimation Methodology for NETL Assessments of Power Plant Performance. National Energy Technology Laboratory, USDOE; 2011.

[78] Griva I, Nash SG, Sofer A. Linear and Nonliner Optimization, Secnd Edition: Society for Industrial and Applied Mathematics (SIAM, 3600 Market Street, Floor 6, Philadelphia, PA 19104); 2009. 